UNIVERSIDADE DE BRASÍLIA

DEPARTAMENTO DE ECONOMIA

MESTRADO PROFISSIONALIZANTE EM ECONOMIA DO SETOR PÚBLICO

HELVIO ANTONIO PEREIRA MARINHO

EFEITOS DA EMENDA CONSTITUCIONAL 41/03 NAS APOSENTADORIAS POR INVALIDEZ NO BRASIL 


\title{
EFEITOS DA EMENDA CONSTITUCIONAL 41/03 NAS APOSENTADORIAS POR INVALIDEZ NO BRASIL
}

\begin{abstract}
Dissertação de mestrado apresentada ao curso de Economia Profissionalizante, Mestrado em Economia do Setor Público, oferecido pelo departamento de Economia da Universidade de Brasília, em cooperação com a Escola Superior de Administração Fazendária do Ministério da Fazenda, como parte dos requisitos para a obtenção do título de Mestre em Economia.

Área de concentração: Mestrado Profissionalizante em Economia - Economia do Setor Público
\end{abstract}

ORIENTADOR: Moisés de Andrade Resende Filho CO-ORIENTADOR: Vander Mendes Lucas

Brasília 


\title{
ANÁLISE DO IMPACTO DA ALTERAÇÃO NORMATIVA NA APOSENTADORIA POR INVALIDEZ NO BRASIL
}

\author{
Esta dissertação foi julgada adequada para a obtenção \\ do título de Mestre em Economia e aprovada em sua \\ forma final pelo Orientador e pela Banca Examinadora.
}

Orientador: Prof. Dr. Moises de Andrade Resende Filho, Departamento de Economia/UnB

Banca Examinadora:

Prof. Dr ${ }^{\mathrm{a}}$. Maria Eduarda Tannuri-Pianto, Departamento de Economia/UnB

Prof. Dr. Bernardo Borba de Andrade, Departamento de Estatística/UnB

Membro suplente:

Prof. Dr. Leandro Golçalves do Nascimento, Departamento de Economia/UnB

Coordenadora do MESP: Prof. Dr ${ }^{\mathrm{a}}$.Maria Eduarda Tannuri-Pianto

Brasília, 10 de fevereiro de 2015. 


\section{DEDICATÓRIA}

Dedico este trabalho aos meus pais, em especial pela dedicação e apoio. 


\section{RESUMO}

Essa dissertação investiga a reação dos servidores públicos federais às alterações restritivas das regras relacionadas à aposentadoria por invalidez introduzidas pela Emenda Constitucional 41 de 2003. Inicialmente, busca-se na literatura fatores que possam impactar os pedidos de aposentadoria por invalidez. Tais fatores são incluídos como controles em um modelo econométrico para comparar o comportamento dos servidores públicos (grupo tratado) com os trabalhadores da iniciativa privada (grupo controle), pois as mudanças nas regras não os atingiram. Utilizam-se dados do total de aposentadorias e aposentadorias por invalidez e do número de acidentes de trabalho dos dois grupos. Com base na estimativa de diferenças em diferenças, constata-se que os servidores públicos reagiram às alterações das regras evitando a aposentadoria por invalidez. Tal reação aproximou o percentual de aposentadorias por invalidez no setor público àquela observada para os trabalhadores do setor privado, o que foi interpretado como uma redução do problema de risco moral.

Palavras-chaves: Previdência Social. Aposentadoria por Invalidez. Incentivos. Risco Moral. 


\begin{abstract}
I investigate the effect on civil servants behavior of more stringent rules for the utilization of disability retirement benefits, which were introduced by the Constitutional Amendment 41 of 2003. I first search the literature for factors that may influence people applications for disability retirement, and use these factors as control variables in an econometric model to compare the behavior of civil servants (treated group) with private sector workers (control group, as the changes in rules for the utilization of disability retirement benefits did not affect them). I use data on the overall number of retirements, retirements due to disability, and accidents at work for the two groups. Based on differences in differences estimates, I find public servants have reacted to changes in rules, avoiding the use of disability retirement benefits. This made the percentage of disability pensions in the public sector converge to that observed for private sector workers. I interpret this result as a reduction in the moral hazard problem.
\end{abstract}

Keywords: Social Security. Disability Retirement. Incentives. Moral Hazard. 


\section{SUMÁRIO}

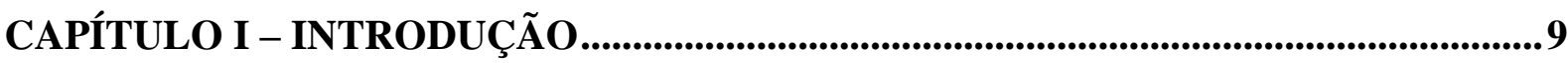

CAPÍTULO II - ANÁLISE DA ESTRUTURA PREVIDENCIÁRIA NO BRASIL ........11

II.1 A PREVIDÊNCIA NO BRASIL E SEUS GRUPOS ....................................................................11

II.2 ALterações naS Regras da PREVIDÊNCIA........................................................................12

II.3 CONSEQUÊNCIAS DAS ALTERAÇÕES NORMATIVAS .............................................................13

II.4 LEGISLAÇÃO DO RGPS.......................................................................................................... 14

CAPÍTULO III - RESPOSTA DOS AGENTES AOS INCENTIVOS OU

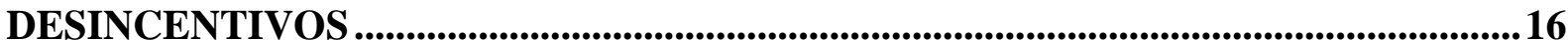

III.1 O PAPEL DAS CONDIÇÕES DE SAÚDE NA UTILIZAÇÃO DE BENEFíCIOS POR DOENÇA ......16

III.2 AS ALTERAÇÕES DE REGRAS E A UTILIZAÇÃO DE BENEFÍCIOS............................................20

III.3 Perícia Médica e Decisão dos Agentes ......................................................................24

III.4 ESCOLHA DO GRUPO DE CONTROLE...................................................................................28

CAPÍTULO IV - O COMPORTAMENTA DA APOSENTADORIA POR INVALIDEZ

NO BRASIL SOB EFEITOS DA EMENDA À CONSTINUIÇÃO No 41 DE 2003 ..........29

IV.1 DESCRIÇÃO DOS DADOS ....................................................................................................29

IV.2 ANÁLISE GRÁFICA .........................................................................................................30

IV.3 MENSURAÇÃO DOS IMPACTOS..........................................................................................36

IV.4 AVALIAÇÃo Do RESULTADO ................................................................................................43

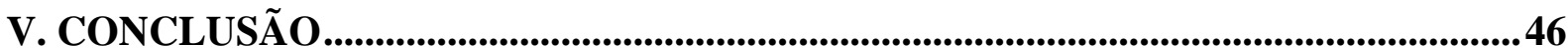

VI. REFERÊNCIAS ................................................................................................................47 


\section{CAPÍTULO I - INTRODUÇÃO}

A Previdência Social constitui uma das principais preocupações dos últimos governos no Brasil (PINHEIRO, 2002). Por um lado é inegável a importância da Previdência Social como política social para manter, na aposentadoria do trabalhador, a sua condição econômica e, consequentemente, o seu bem estar. Contudo, nos últimos anos os constantes déficits da Previdência Social atrelados a projeções pessimistas têm colocado em risco as contas nacionais (NAJBERG e IKEDA, 1999), ensejando mudanças nas normas, inclusive constitucionais. Estas mudanças vão no sentido de diminuir os custos previdenciários, restringindo os benefícios dos futuros aposentados, principalmente daqueles oriundos do setor público. Entretanto, como os agentes econômicos agem conforme seus interesses, nem sempre as políticas públicas alcançam os objetivos inicialmente planejados.

A Emenda à Constituição nº 41 de 2003 (EC 41/03), com vigência a partir de janeiro de 2004 e no intuito de diminuir os gastos com aposentadoria por invalidez do servidor público, alterou as regras de concessão, reduzindo o valor do benefício dos futuros aposentados. Tendo em vista que esse tipo de benefício é de risco, provocado por um problema de saúde inesperado ou ainda por um acidente, seria razoável supor um efeito nulo da EC 41/03 no número de aposentadorias por invalidez do servidor público. Contudo, há indícios de que não foi bem este o caso.

A presente dissertação tem como objetivo testar a hipótese de efeito nulo da EC 41/03 no número de aposentadorias por invalidez do servidor público. Para tanto, compara o número de aposentadorias por invalidez entre os servidores públicos e os trabalhadores da iniciativa privada, não afetados pela alteração normativa, antes e depois do início de vigência da EC $41 / 03$.

Esta dissertação está organizada da seguinte forma: o segundo capítulo apresenta os tipos de previdência no Brasil e as alterações ocorridas em suas regras de concessão; o terceiro capítulo apresenta alguns modelos previamente utilizados para medir os impactos de alterações conjunturais ou de regras sobre os benefícios sociais com exemplos brasileiros; o quarto capítulo apresenta a comparação entre o número de aposentadorias por invalidez no serviço público e no setor privado, mensurando o impacto da EC 41/03; por fim, o quinto capítulo apresenta as conclusões do trabalho, destacando-se a constatação do impacto da 
adoção de regras mais restritivas no uso da aposentadoria por invalidez no serviço público com a queda no número dessa modalidade de aposentadoria. 


\section{CAPÍTULO II - ANÁLISE DA ESTRUTURA PREVIDENCIÁRIA NO BRASIL}

A Previdência Social no Brasil é um direito social, previsto no art. $6^{\circ}$ da Constituição Federal de 1988 (CF/88) entre os Direitos e Garantias Fundamentais, devendo, segundo seu art. $\mathrm{n}^{\circ}$ 201, garantir renda não inferior ao salário mínimo ao trabalhador e a sua família nas seguintes situações:

"I - cobertura dos eventos de doença, invalidez, morte e idade avançada;

II - proteção à maternidade, especialmente à gestante;

III - proteção ao trabalhador em situação de desemprego involuntário;

IV - salário-família e auxílio-reclusão para os dependentes dos segurados de baixa renda;

$V$ - pensão por morte do segurado, homem ou mulher, ao cônjuge ou companheiro e dependentes."

\section{II.1 A Previdência no Brasil e seus grupos}

No Brasil, a Previdência Social pode ser separada em três regimes distintos:

1. O Regime Geral de Previdência Social (RGPS), previsto no art. 201 da CF/88, com caráter contributivo e de filiação obrigatória para os empregadores, empregados assalariados, domésticos, autônomos, contribuintes individuais e trabalhadores rurais.

2. O Regime Próprio de Previdência Social (RPPS), previsto no art. 40 da CF/88, compulsório para o servidor público do ente federativo que o tenha instituído, com teto e subtetos definidos pela Emenda Constitucional no 41/2003. Cabe lembrar que não inclui os empregados das empresas públicas, os agentes políticos, servidores temporários e detentores de cargos de confiança, os quais são todos filiados obrigatoriamente ao RGPS.

3. O Regime de Previdência Complementar (RPC), previsto no art. 202 da CF/88, que se diferencia dos demais, principalmente por ser facultativo. No Brasil, o RPC é dividido em uma parte operada pelas entidades abertas, em que a entrada é livre a qualquer pessoa, e outra parte controlada pelas Entidades Fechadas de Previdência Complementar (EFPC), ou fundos de pensão, na qual a entrada é limitada aos empregados de empresas, ditas patrocinadoras, e aos associados ou membros de 
associações, entidades de caráter profissional, classista ou setorial, sendo nesses casos instituidores. A principal característica da parte operada pelas EFPCs é a coparticipação, ou seja, assim como no RPPS e no RGPS, a empregadora participa junto com seu funcionário, no que exceder o teto do INSS, no fundo previdenciário da EFPC.

\section{II.2 Alterações nas regras da Previdência}

O RPPS sempre tem sido o foco de muita discussão por ser considerado deficitário e por se acreditar que tal déficit tende a aumentar descontroladamente ao longo do tempo. A despeito da discussão sobre a veracidade de tais fatos, é fato que as grandes mudanças ocorridas no RPPS nas últimas décadas, geralmente de caráter restritivo, visavam diminuir os custos do RPPS, tendo em vista projeções que colocavam em risco as contas nacionais (NAJBERG; IKEDA, 1999). Dentre as grandes mudanças ocorridas no RPPS, destacam-se as Emendas Constitucionais $n^{\circ} 20$, de 16/12/98, nº 41, de 31/12/03 e nº47, de 05/07/2005, que alteraram, sobretudo, as regras de aposentadoria dispostas no art. 40 da CF/88. Segundo a Secretaria de Estado de Educação do Distrito Federal (2014), tais mudanças podem ser resumidas como segue.

\section{II.2.1 Emenda Constitucional $n^{\circ} 20$ (EC 20/1998):}

“A Emenda Constitucional $N^{o} 20$, de 16 de dezembro de 1998, estabeleceu limites para as aposentadorias integrais, tais como idade mínima de 60 anos para homens e de 55 anos para mulheres, além da exigência de 10 anos de serviço público e cinco anos no cargo em que se der a aposentadoria. Também extinguiu a aposentadoria proporcional para os servidores que ingressaram no serviço público após sua promulgação e transformou tempo de serviço em tempo de contribuição, impossibilitando qualquer forma de contagem de tempo de contribuição fictício.

Em seu art. $8^{\circ}$, foi criada uma regra de transição para os servidores que ingressaram até 16 de dezembro de 1998 e foi estabelecido um pedágio de $20 \%$ para as aposentadorias integrais e de $40 \%$ para proporcionais. Esta Emenda restringe a possibilidade de percepção de mais de uma aposentadoria pelo servidor público e a acumulação de proventos com remuneração de cargo, excetuando-se os casos acumuláveis. Foram extintas as aposentadorias especiais, ressalvando aquelas que prejudiquem a saúde ou a integridade 
física, bem como a do professor no exercício das funções de magistério na educação infantil e no ensino fundamental e médio.

\section{II.2.2 Emenda Constitucional no 41 (EC 41/03):}

“Em 19 de dezembro de 2003 foi promulgada a Emenda Constitucional $N^{o} 41$, publicada em 31/12/2003, que retirou a paridade entre os servidores ativos $e$ aposentados no reajuste dos benefícios. A EC 41/03 instituiu uma nova regra de cálculo dos proventos, definida pela Lei 10.887/04, levando em consideração as remunerações utilizadas como base para as contribuições do servidor no Regime Próprio de Previdência Social e no Regime Geral de Previdência Social. Com a Emenda Constitucional $N^{o} 41$, a aposentadoria proporcional ditada pela regra de transição da Emenda Constitucional $N^{o} 20$ foi extinta e foram criadas novas regras de transição: uma prevista pelo art. $2^{\circ}$, para os que ingressaram até a publicação da EC 20/98 (cálculo pela média e sem paridade); e outra regra prevista pelo art. $6^{o}$, para os que ingressaram até a publicação da EC 41/03 (cálculo pela última remuneração e paridade)”.

\section{II.2.3 Emenda Constitucional no 47 (EC 47/2005):}

“A Emenda Constitucional $N^{o} 47$, de 05 de julho de 2005, em seu art. $3^{o}$, criou uma nova regra de transição para servidores que tenham ingressado no serviço público até 16/12/1998, resguardando a paridade e o cálculo dos proventos integrais desde que preenchidos os requisitos exigidos no citado artigo. "

Ressalta-se que a EC 41 , em seu artigo $3^{\circ}, \S 1^{\circ}$, "instituiu o abono de permanência para os servidores que tenham cumprido os requisitos para aposentadoria voluntária e que optem por permanecer em atividade, fazendo jus ao equivalente ao valor de sua contribuição previdenciária”. Esta Emenda também alterou a forma de calcular as pensões, regulamentada no art. $2^{\circ}$ da Lei 10.887.

\section{II.3 Consequências das Alterações Normativas}

Pelo exposto acima, é correto dizer que houve uma piora nos termos de concessão da aposentadoria por invalidez. Se antes de 2003 a base de cálculo era a última remuneração do servidor no cargo efetivo em que ocorreu a aposentadoria (integralidade), a partir de 2004, com a EC 41/03, "a base de cálculo passou a ser a média aritmética simples das $80 \%$ maiores 
remunerações do servidor desde julho de 1994, corrigidas monetariamente, e observados os critérios do artigo $1^{\circ}$ da Lei $n^{\circ} 10.887 / 04 "$ (SOARES, 2012). Além disso, não há mais garantias do aposentado receber os mesmos reajustes dos servidores ativos com o fim da paridade. Assim, mesmo nos casos em que o coeficiente aplicado for de 100\%, como a base de cálculo passou a ser sempre menor, a aposentadoria também será reduzida.

\section{II.3.1 Aposentadoria por Invalidez no RPPS:}

A redação anterior à EC 41/03 do Art. 40, § $1^{\circ}$, inciso I da CF/88 garantia a obtenção da aposentadoria por invalidez integral no RPPS. Para obter o benefício com proventos iguais à última remuneração anterior ao motivo da aposentadoria, era exigido acidente de trabalho, ou seja, durante o serviço. Também eram aceitas doenças em decorrência do trabalho, como a Lesão por Esforço Repetitivo (LER) ${ }^{1}$ para digitadores, ou ainda doenças graves previstas em lei, como hanseníase, paralisia irreversível e mal de Parkinson. No caso do acidente ter sido sofrido fora do trabalho, a remuneração será proporcional ao tempo de contribuição (Júnior, 2014).

Entretanto, a partir de 31.12.03, com a Vigência da EC 41/03, o Art. 40, § $1^{\circ}$, inciso I da $\mathrm{CF} / 88$ passou a calcular os proventos da aposentadoria por invalidez por doença prevista em lei à média aritmética dos proventos integrais, sem paridade, ou seja, a remuneração não está vinculada à remuneração do servidor ativo. Também a aposentadoria proporcional, oriunda de Doença Incapacitante, sofreu alterações sendo calculada pela Média aritmética simples e proporção do cálculo por dias trabalhados.

\section{II.3.2 Abono-permanência}

A instituição do "abono permanência", isto é, o pagamento de $11 \%$ do salário sobre o excedente do teto de aposentadoria do RGPS àqueles que satisfazem aos critérios de aposentadoria, também alterou os incentivos dados aos funcionários públicos a permanecerem por mais tempo na ativa.

\section{II.4 Legislação do RGPS}

Entre 2002 e 2012, não houve alteração na legislação com impacto no valor do benefício devido ao segurado do RGPS em caso de incapacidade para o trabalho. Por isso, a renda mensal recebida como aposentadoria por invalidez continuou sendo calculada à base de $100 \%$

\footnotetext{
${ }^{1}$ São lesões nos sistemas musculoesquelético e nervoso causadas por tarefas repetitivas, como digitação.
} 
sobre o salário de benefício ${ }^{2}$, podendo ser acrescido de $25 \%$ caso o beneficiário necessite de auxílio permanente de uma pessoa.

\footnotetext{
${ }^{2}$ Média apurada sobre os salários de contribuição, corrigidos mensalmente, dos maiores salários de contribuição de $80 \%$ do período contributivo.
} 


\section{CAPÍtULO III - RESPOSTA DOS AGENTES AOS INCENTIVOS OU DESINCENTIVOS}

Espera-se que todo agente econômico responda a incentivos, sendo que, em geral, o incentivo se dá via preço. Se por um lado um preço mais baixo aumenta o consumo de um bem, por outro tende a reduzir sua oferta pelas firmas. Mas os incentivos não se restringem ao mecanismo de preços. Por exemplo, na tentativa de aumentar a mobilidade urbana e diminuir a poluição na Cidade do México, o governo local introduziu o chamado "rodízio de carros". Como acontece em São Paulo, todo dia útil 20\% dos automóveis (placas terminadas em 2 algarismos distintos) são proibidos de circular na capital mexicana. Conforme apontam Levitt e Dubner (2014), o efeito do rodízio de carros na Cidade do México foi um aumento na frota de carros antigos, pois os proprietários trocaram um carro novo por dois outros mais antigos com placas diferentes a fim de poder circular todos os dias. Como consequência, o efeito final da política de rodízio de carros na Cidade do México foi o aumento na poluição e manutenção do fluxo de veículos. Assim, é fundamental analisar as políticas públicas, pois apesar de bem intencionadas nem sempre produzem o resultado preconizado.

Este capítulo tem como objetivo analisar o papel das políticas públicas na utilização de benefícios por invalidez e no mercado de trabalho.

Para tal, serão utilizados modelos de trabalhos realizados em outros países para mensurar os impactos das condições de saúde, das alterações de regras e da perícia médica na utilização de benefícios por invalidez e no comportamento do mercado de trabalho. As conclusões obtidas serão contrastadas com os respectivos exemplos no Brasil. Também será apresentada a série histórica do número de acidente de trabalho.

Essa análise busca identificar fatores que possam explicar a variação ocorrida na concessão de benefícios por invalidez no país.

\section{III.1 O papel das condições de saúde na utilização de benefícios por doença}

Ao abordar o tema "impacto das condições de saúde na utilização de benefícios por doença”, espera-se uma queda na utilização desses benefícios diante de uma melhora nas condições de saúde da população, e vice-versa.

Com vistas a testar essa hipótese, deve-se mensurar possíveis alterações na saúde da população. Para tal, segundo Jönsson et al. (2010), pode-se usar três variáveis: mortalidade, 
pesquisas com autoproclamação ou utilização de cuidados médicos, como número de internações.

Em estudo feito na Suécia (JÖNSSON et $a l ., 2010$ ), pôde-se identificar nos grupos ${ }^{3}$ com $^{2}$ as menores melhoras na saúde, tanto nos critérios da pesquisa autointitulada quanto na utilização de cuidados médicos, um aumento na utilização do seguro por invalidez em relação aos demais. Entretanto, as medidas de saúde da população apresentaram resultados ambíguos: a sensível queda na mortalidade deveria indicar uma melhora, não confirmada nas pesquisas com questionário de auto relato ou nos dados sobre utilização de cuidados médicos.

Uma explicação é o fato de uma queda na taxa de mortalidade, ao deixar vivas por mais tempo pessoas consideradas incapacitadas para o trabalho, afeta negativamente a condição geral de saúde da população. Isso ocorre porque a redução da mortalidade pode revelar apenas melhoras na tecnologia do sistema de saúde. Tal avanço permitiria prolongar o número de anos de vida, mas não necessariamente o período em que as pessoas permanecem aptas ao trabalho.

No Brasil, também ocorreu uma queda na taxa de mortalidade entre 1996 e 2013. Isso pode ser verificado no fato de as pessoas passarem a falecer com idades mais avançadas. No Gráfico 1, identifica-se um aumento significativo da mortalidade das pessoas com 75 anos ou mais. Em contraponto, há uma queda acentuada na mortalidade de indivíduos até 44 anos. Já a mortalidade nas demais faixas de idade permaneceu praticamente inalterada.

\footnotetext{
${ }^{3}$ Nesse caso, mulheres e a faixa etária entre 45 e 54 anos em ambos os gêneros, entre 1970 e 2000.
} 


\section{Gráfico 1 - Evolução da Participação por Grupo Etário na Mortalidade no Brasil}

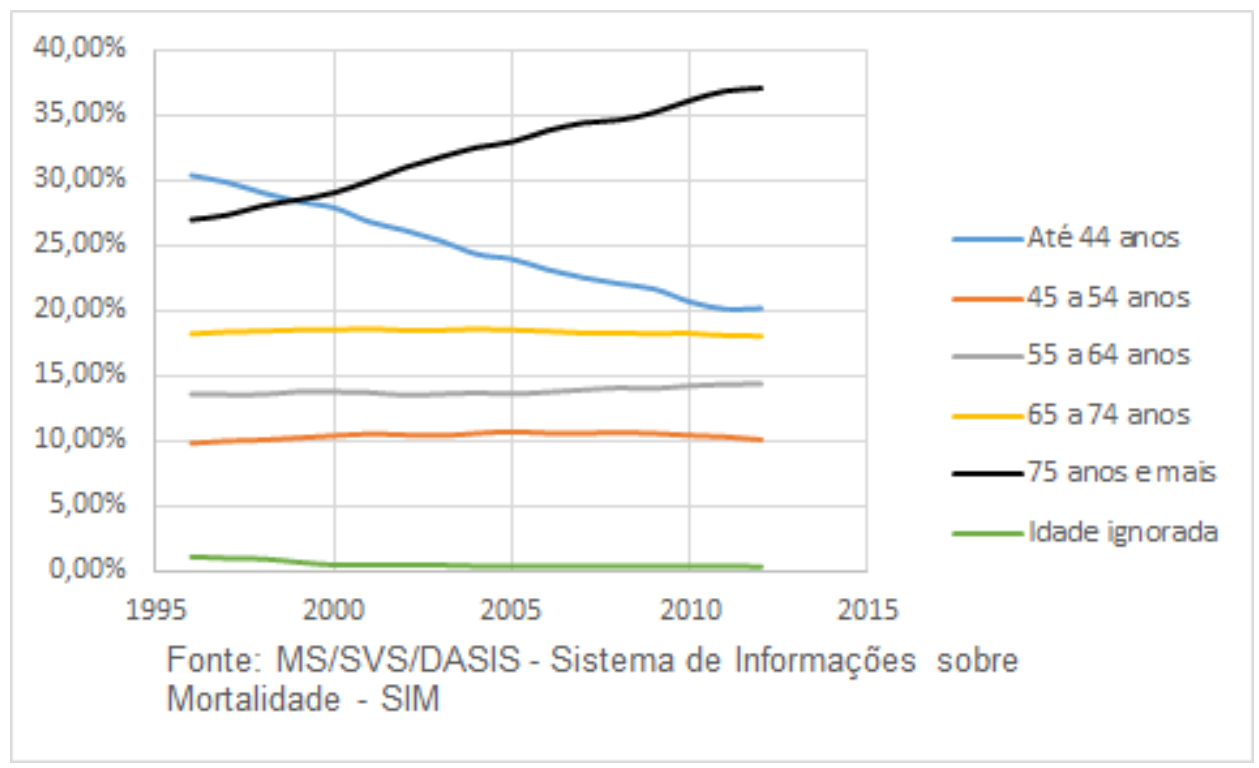

O outro parâmetro de comparação é a utilização de cuidados médicos. Para sua análise, utilizam-se como variáveis o número de internações registrados no Sistema Único de Saúde (SUS) e a média de dias em que o paciente permanece internado nos hospitais ${ }^{4}$. O número de internações é apresentado logaritmizado para melhor visualização. Durante o período de janeiro de 1998 a dezembro de 2013, o uso de cuidados médicos no Brasil permaneceu praticamente inalterado, conforme apresentado no Gráfico 2.

\footnotetext{
${ }^{4}$ Média de permanência das internações referentes às Autorização de Internação Hospitalar (AIH) aprovadas no período, computadas como internações.
} 


\section{Gráfico 2 - Evolução Mensal da Média de Permanência de Internações Hospitalares e do Número de Internações (logaritmizado) no Brasil}

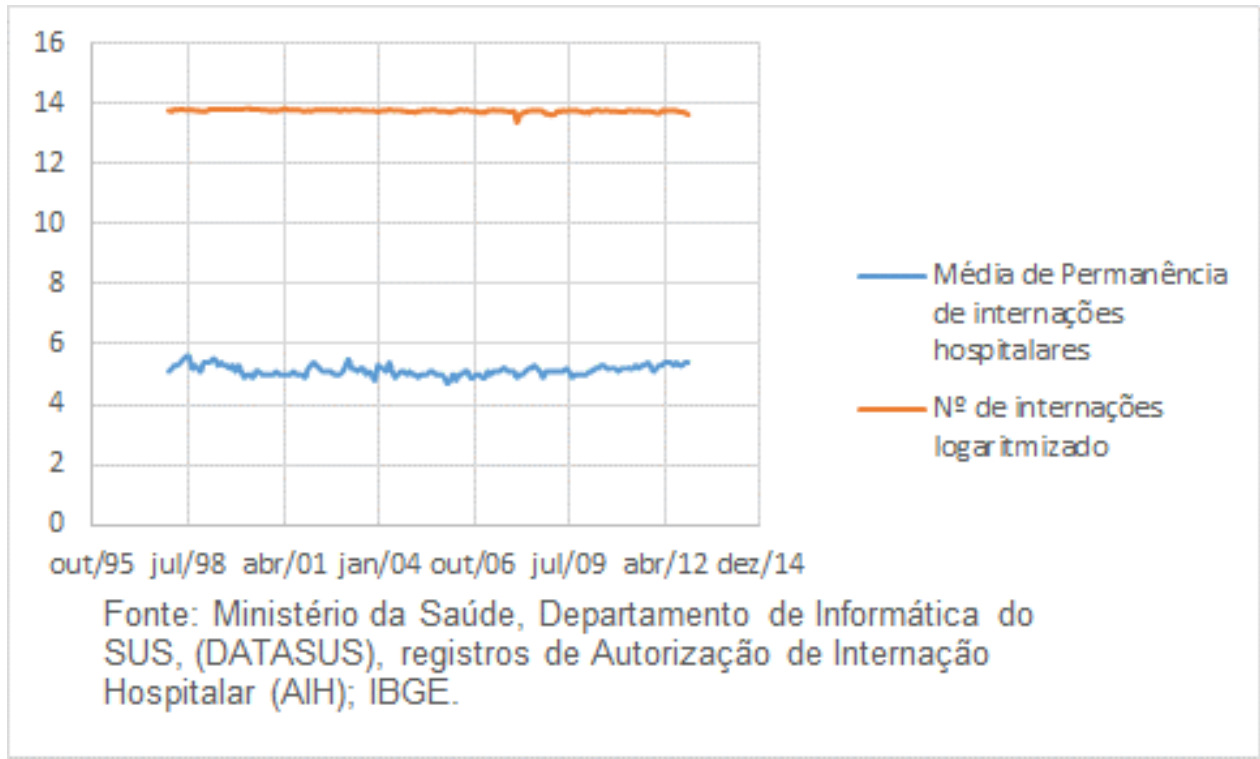

De acordo com o Gráfico 3, também não se observa nenhuma tendência nos gastos públicos com saúde em relação ao Produto Interno Bruto (PIB). Com base nisso, é possível conjecturar que a redução na mortalidade se deve a outros fatores, como o declínio na fecundidade, o maior acesso ao saneamento básico e educação (BATISTELLA, 2007), ou ainda, devido a melhora na tecnologia da saúde.

Gráfico 3 - Gasto federal com saúde como proporção do PIB (referência ano 2000)

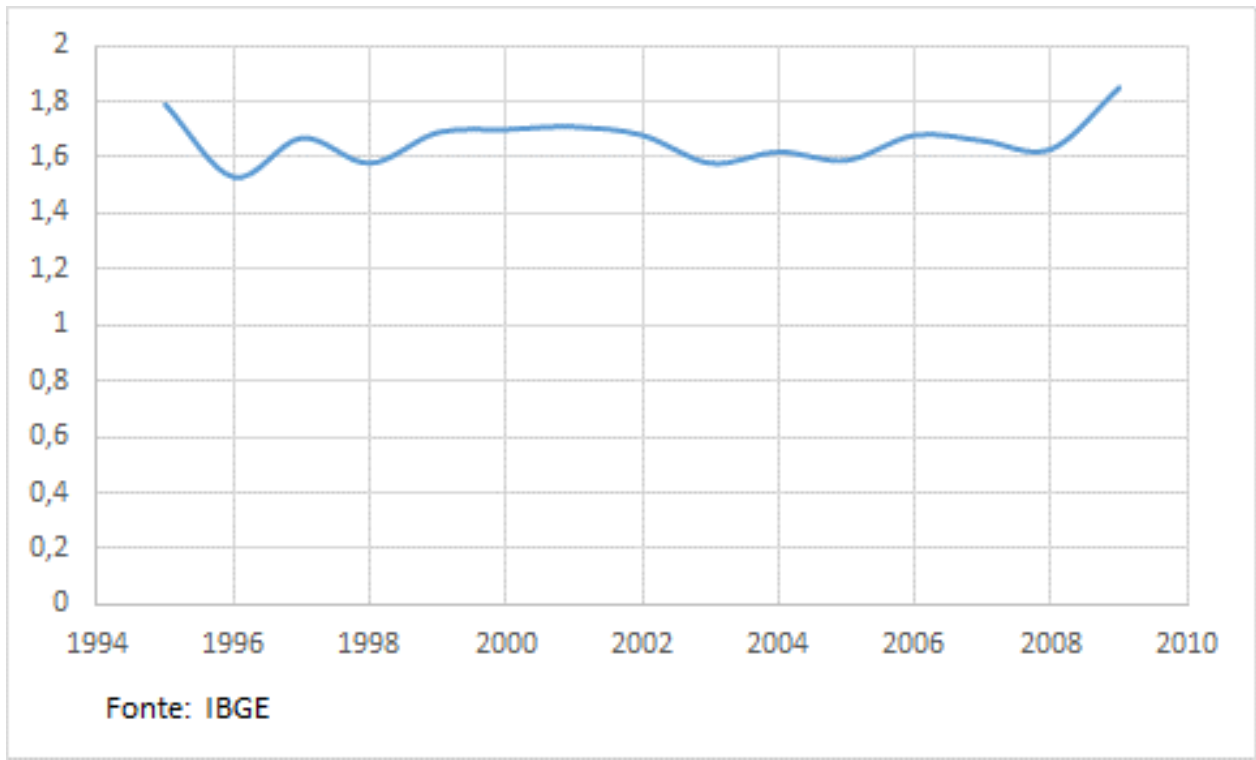




\section{III.2 As alterações de regras e a utilização de benefícios}

Dentre os fatores que alteram a decisão das pessoas em relação aos benefícios, destaca-se o grau de proteção dos segurados, isto é, o quanto este receberá no caso fortuito. Outro item importante é a elegibilidade ao benefício. Afinal, o segurado deve se enquadrar a determinados critérios para recebe-lo. Entre 1960 e 2009, na Suécia, houve importantes alterações nas regras de concessão de benefícios. Duas delas, em 1970 e em 1972, apresentaram caráter menos restritivo, enquanto em 1991 e em 1997, tornaram as regras mais rígidas.

A reação dos agentes a essas alterações, estudadas em Jönsson et al. (2010), será comparada com a reação no Brasil. Para tal, serão comparadas as reações à comunicação de mudanças nas normas, os impactos na utilização do benefício e no mercado de trabalho, e o papel da perícia médica nas escolhas dos agentes.

\section{III.2.1 Antecipação}

No estudo da reação dos agentes, identificam-se mudanças em seus comportamentos antes do início da vigência de novas normas, já que é comum uma notificação prévia. No caso sueco (JÖNSSON et al. 2010, p. 43), houve antecipação diante da comunicação de aumento no rigor das regras. Em 1997, foi identificado um aumento no número de benefícios concedidos, sobretudo provocado pela antecipação de pessoas que não seriam mais aptas ao benefício em $1998^{5}$.

No Brasil, diante das alterações previstas para 2004, houve um elevado crescimento do número de aposentadorias programadas (aposentadorias integrais e proporcionais) dos servidores já elegíveis ao benefício à época (vide Gráfico 4).

\footnotetext{
${ }^{5}$ Principalmente pessoas entre 60 e 64 anos, que em 1970 se tornaram elegíveis a receber o seguro caso não encontrassem emprego entre 1 e 2 anos, independente de incapacidade, o que terminou em 1997.
} 


\section{Gráfico 4 - Efeito mensal nos tipos de aposentadorias da antecipação provocada pela comunicação prévia de mudança nas regras de aposentadoria}

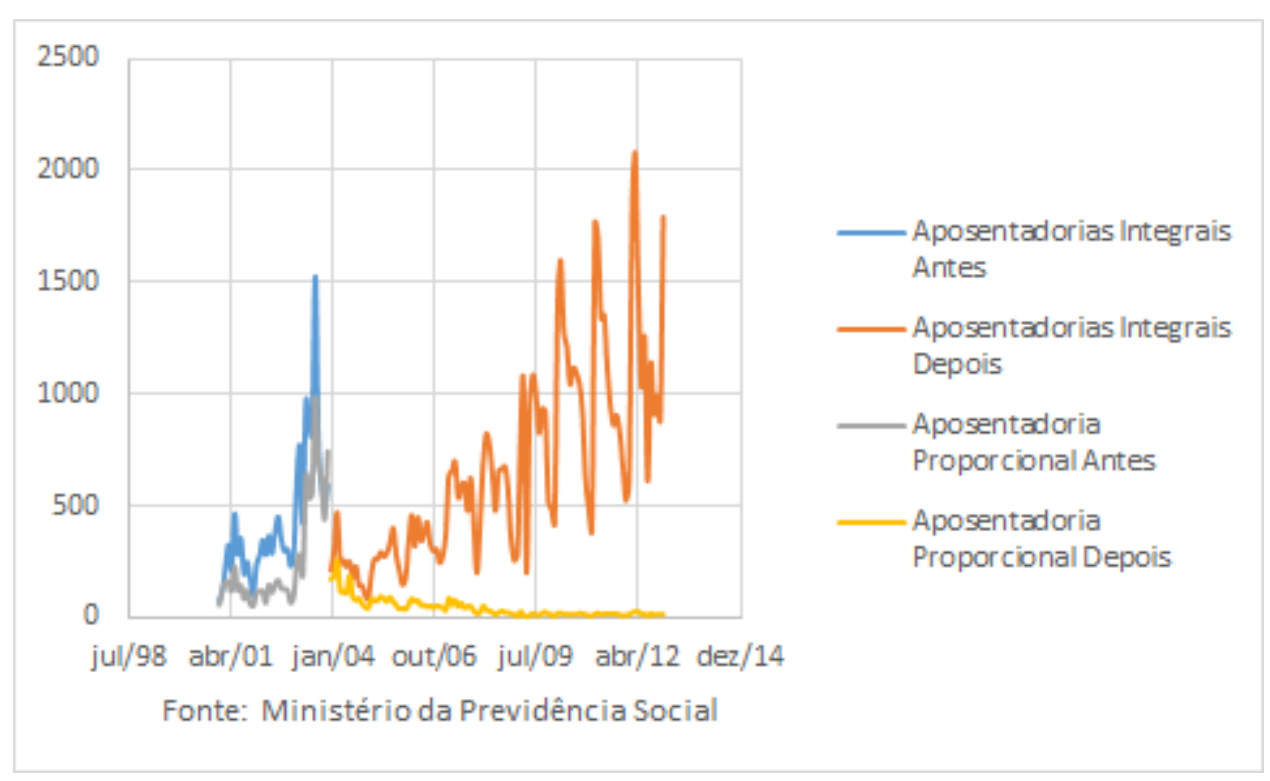

Como mostra o Gráfico 5, diante das alterações previstas para 2004, também houve um grande crescimento de aposentadorias por invalidez no Brasil em 2003, seguida por uma queda nos períodos subsequentes.

\section{Gráfico 5 - Número anual de aposentadorias por invalidez no RPPS}

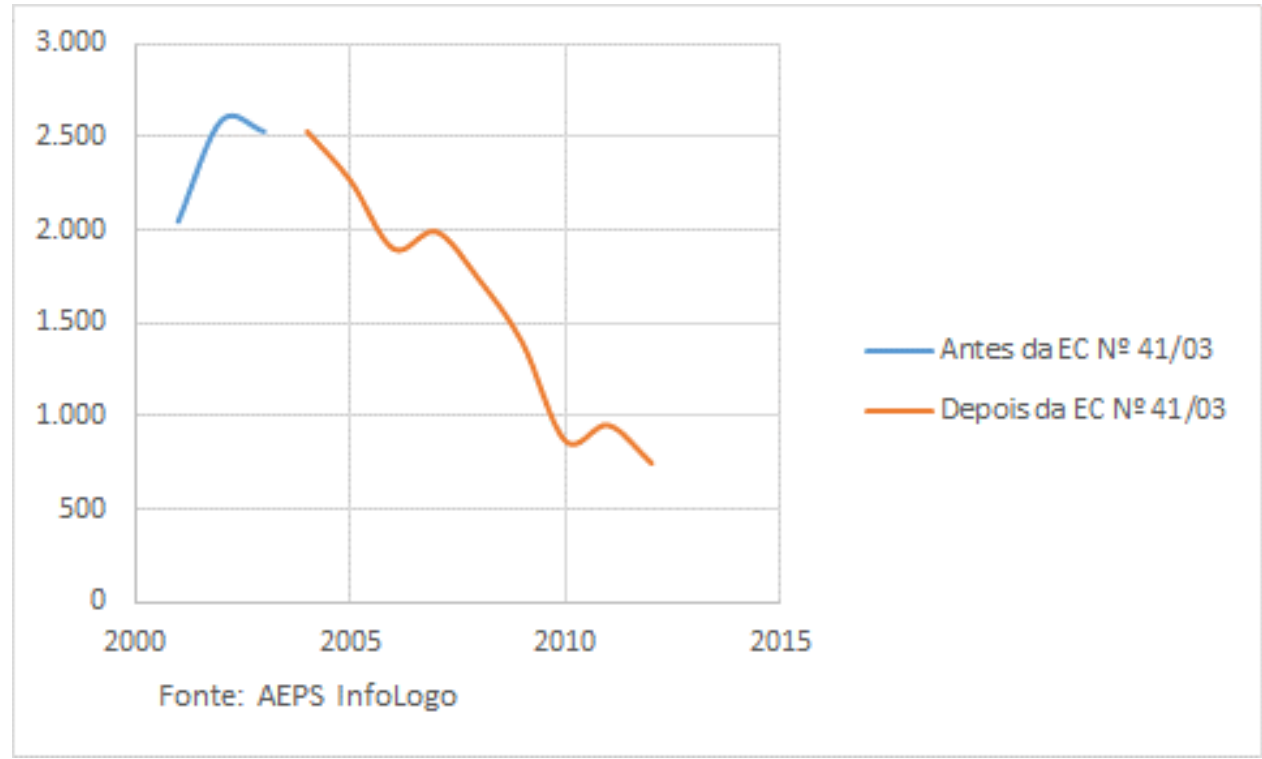

\section{III.2.2 Utilização}

Sobre a utilização do seguro por invalidez, segundo Jönsson (2004 e 2010) é correto afirmar que regras mais brandas, tanto na ampliação da exigibilidade quanto no acréscimo dos 
valores a serem recebidos, aumentaram significativamente seu uso na Suécia. Posteriormente, com o aumento na rigidez caiu o número de benefícios concedidos. Em contraponto, houve aumento na demanda por outros benefícios, como o seguro desemprego e o seguro por doença.

O caso brasileiro também revelou uma tendência semelhante. Em 2004, diante de regras mais restritivas, houve uma sensível queda no número de aposentadorias por invalidez. Tal comportamento será melhor analisado no próximo capítulo.

\section{III.2.3 Impacto de Alteração de Regras no Mercado de Trabalho}

Algumas mudanças na utilização dos benefícios por invalidez podem afetar a demanda por trabalho (JÖNSSON et al. 2010). Para ilustrar isso, destacam-se as seguintes alterações de regras na Suécia: inelegibilidade à invalidez daqueles aptos a obter outro emprego, mesmo diferente do anterior; maior controle administrativo nos processos de concessão; e incentivos econômicos para o trabalhador não antecipar a aposentadoria, completando a idade mínima para se retirar. O resultado no mercado de trabalho foi uma diminuição do desemprego no grupo de 60 a 64 anos em relação ao grupo de 55 a 59 anos.

Em outro exemplo, foi possível constatar uma diminuição na oferta de trabalho entre trabalhadores de 45 a 59 anos. Segundo Gruber (2000), isso foi em decorrência de uma equiparação, em 1987, dos valores recebidos com seguro por invalidez pelos demais empregados canadenses com os que trabalhavam na cidade de Quebec, o que significou um ganho de até $36 \%$.

No Brasil, houve um envelhecimento da população ativa, tanto dos trabalhadores ligados ao RGPS, não afetados por mudanças de regras, quanto dos servidores públicos. Entretanto, percebe-se no Gráfico 6 uma tendência mais acentuada no RPPS. 


\section{Gráfico 6 - Comparação entre o RGPS e o RPPS da evolução anual da participação da faixa etária com mais de 50 anos no Mercado de Trabalho}

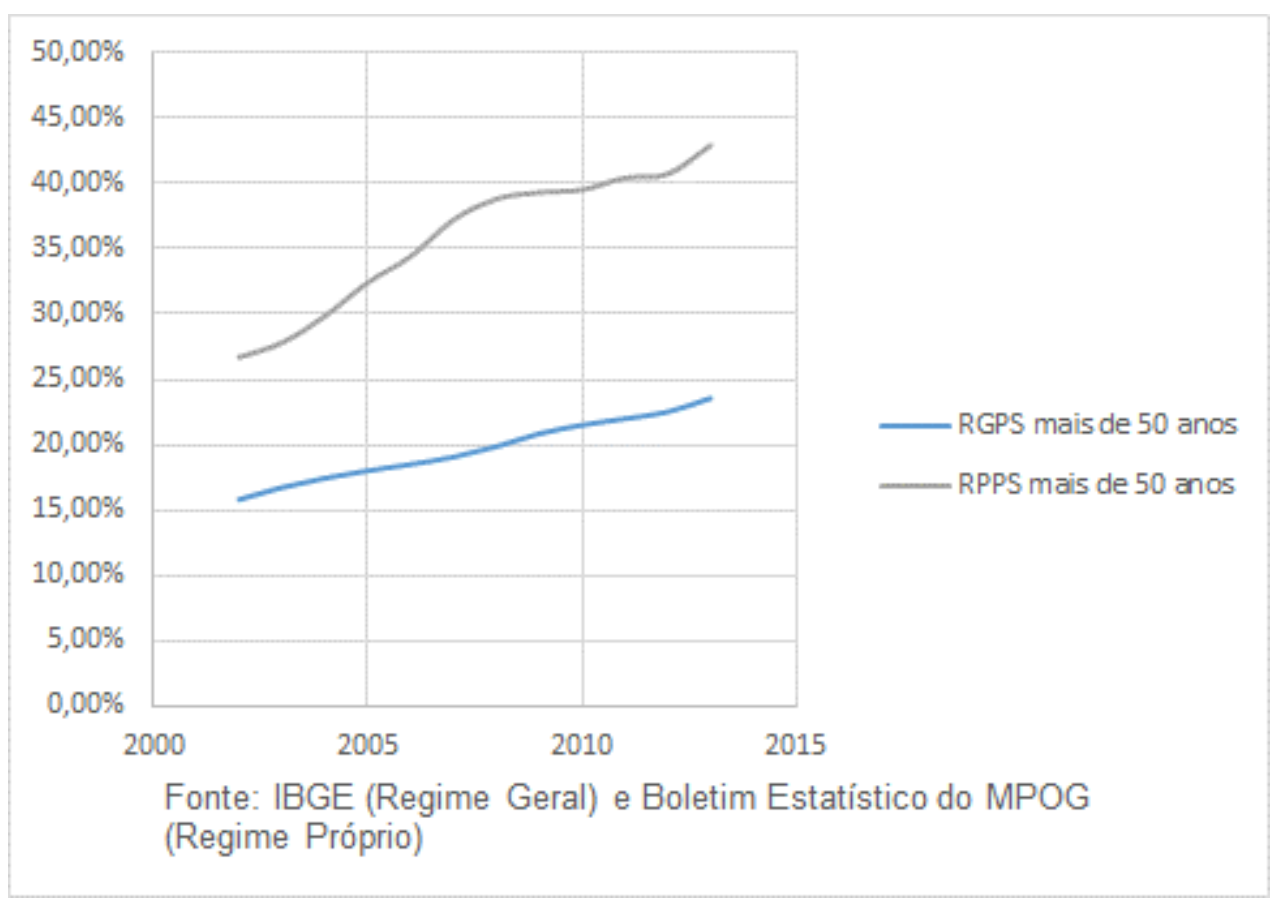

\section{III.2.3 a) Abono Permanência}

Para compreender esse fenômeno, vale ressaltar o aspecto previdenciário. Desde a EC 20/98, o percentual de aposentadorias com proventos proporcionais é decrescente, sendo essa queda associada às "dificuldades impostas pela reforma previdenciária brasileira, a qual introduziu a exigência de idade mínima, o fim da paridade entre proventos de ativos e inativos, pedágios e redutores sobre os proventos proporcionais, entre outras medidas." (GOSMANN, 2014).

Em 2003, a EC 41/03 instituiu o abono permanência. Conforme dito no Capítulo 2, tratase de um ganho pecuniário ${ }^{6}$ para os que já cumpriram os requisitos para aposentadoria voluntária e permanecem na ativa. De acordo Gosmann (2014), isso significou um prolongamento médio de dois anos para os homens e quatro anos para as mulheres na permanência na ativa (vide Gráfico 7).

\footnotetext{
${ }^{6}$ Além de não contribuir com $11 \%$ do valor do salário que exceder o teto do INSS ao se aposentar, acrescenta essa mesma quantia ao salário. Portanto, recebe $22 \%$ a mais sobre essa base de cálculo em comparação com o que receberia de aposentadoria.
} 


\section{Gráfico 7 - Evolução anual da idade de aposentadoria no RPPS}

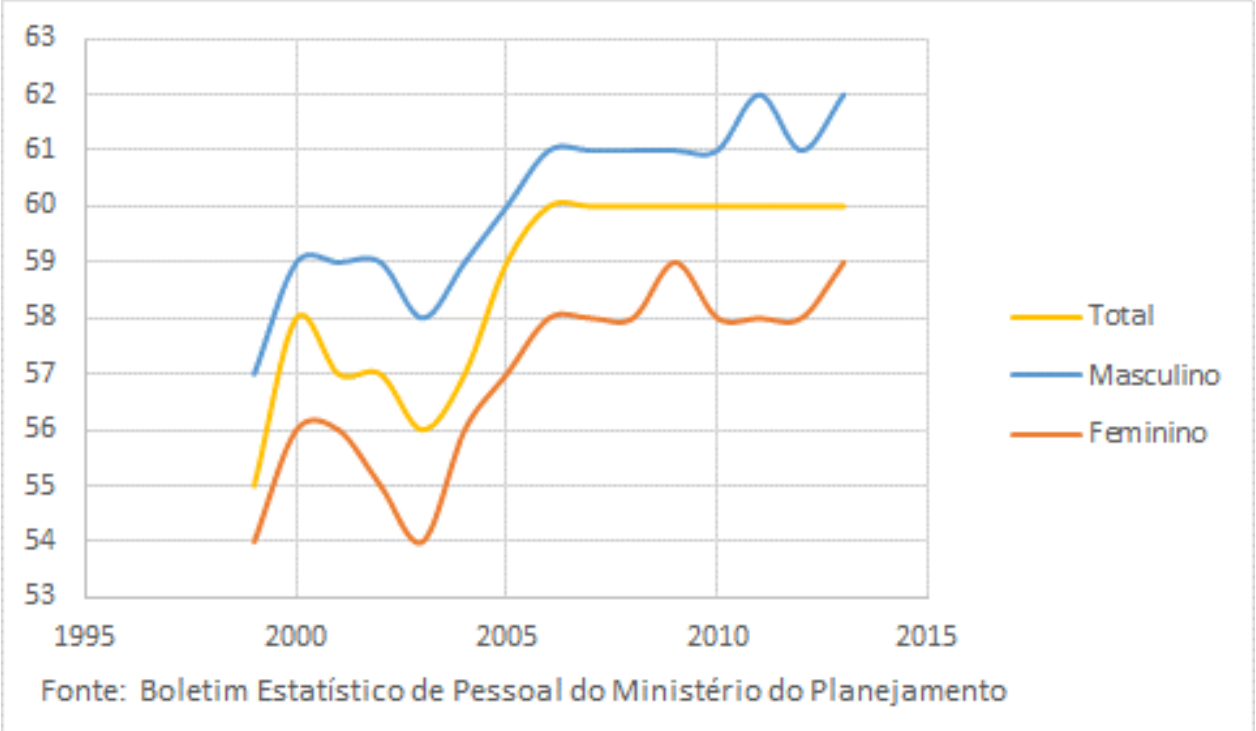

Parte desse aumento pode ser associado às mudanças na aposentadoria por invalidez, uma vez que as pessoas com mais anos de trabalho foram menos afetadas, ou seja, pessoas aptas a se aposentar por invalidez podem retardar sua aposentadoria não só por causa do abono, mas para garantir um percentual maior do valor a receber.

\section{III.3 Perícia Médica e Decisão dos Agentes}

Foram dados alguns exemplos relacionando a utilização de benefícios ligados a saúde, passando a impressão que seu uso está de acordo com o interesse das pessoas, ou seja, elas decidiriam quando utilizar ou não esse direito. Mas se deve ressaltar que o seguro-saúde depende de um fator primordial: um problema de saúde. Embora uma pessoa tendo uma vida sedentária ou sendo fumante possa ser considerada de hábitos não saudáveis, ter uma doença não é algo que se possa escolher. O que explicaria então esse comportamento?

O risco moral consiste em uma mudança de hábito do agente econômico diante de um incentivo, visando apenas o seu interesse, o que muitas vezes está em desacordo com a ética ou com uma visão rigorosa da própria lei. Nesse caso, o agente tende a aumentar ou diminuir o uso de um benefício de acordo com o incentivo oferecido, aproveitando-se de alguma brecha normativa. Em se tratando de um problema de saúde, é importante analisar se a perícia médica pode desestimular a procura pelo benefício. Para responder a essa questão utilizaremos a análise a seguir. 


\section{III.3.1 Estudo da Reação à Perícia Médica}

O seguro-doença ${ }^{7}$, ou seguro-saúde, na Suécia procura recompor a renda dos dias parados por motivo de doença, seja de curta duração, como uma gripe, seja por períodos mais longos, como uma doença crônica. Johanson e Palme (2004) realizaram um estudo sobre a mudança nos períodos de afastamento em decorrência de uma alteração de caráter restritivo nas regras. A restrição significou reduzir o valor a receber do seguro para períodos curtos de afastamento com a diminuição do percentual do salário a receber como indenização. Assim, houve uma queda gradual para afastamentos de até 90 dias, permanecendo inalterado após esse período. Portanto, o risco moral nesse caso pode ser revelado na diminuição de afastamentos em períodos curtos ou no prolongamento nos afastamentos longos. Além disso, após 7 dias de afastamento a perícia é obrigatória, o que também desencorajaria a ausência a partir desse período.

Após analisar as alterações antes e depois da mudança das regras, observou-se uma tendência ambígua no tempo de licença. Houve queda nas abstenções em períodos curtos, inclusive mais acentuada após 7 dias $^{8}$, porém, como o custo aumentou nos retornos antes de 90 dias, a incidência de afastamentos acima de 90 dias também subiu, causando, no geral, uma indesejada alta na média total de dias parados.

No Brasil, houve elevação no número total de exames periciais entre 2001 e 2012. Os dados ilustrados no Gráfico 8 representam exames realizados no RGPS e no RPPS. Cabe ressaltar que a queda acentuada em 2006 foi em decorrência do processo no INSS de substituição dos médicos credenciados por médicos concursados (ANSILIERO e DANTAS, 2008).

\footnotetext{
${ }^{7}$ Tradução livre para "sickness insurance".

${ }^{8}$ Confirmou-se a hipótese de uma preferência por evitar perícia, ou seja, $\beta 2>B 3$, sendo $\beta 2$ ausência de 4 a 7 dias e 33 de 8 a 90 dias.
} 
Gráfico 8 - Números de exames médico-periciais realizados de 2001 a 2012

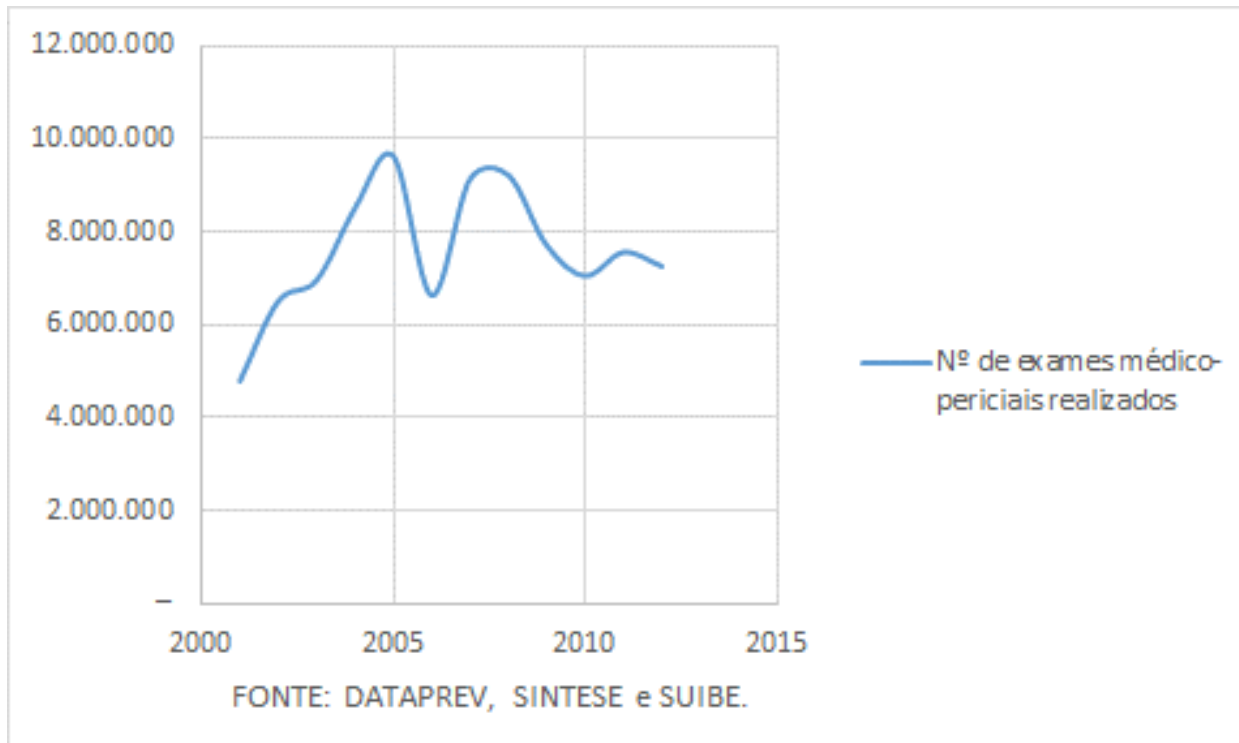

Os gastos com perícias médicas realizadas em servidores também mostraram elevação de 2001 a 2012, conforme mostrado no Gráfico 9.

Gráfico 9 - Evolução anual dos Gastos com Perícia Médica em Servidor Público de 2001 a 2012

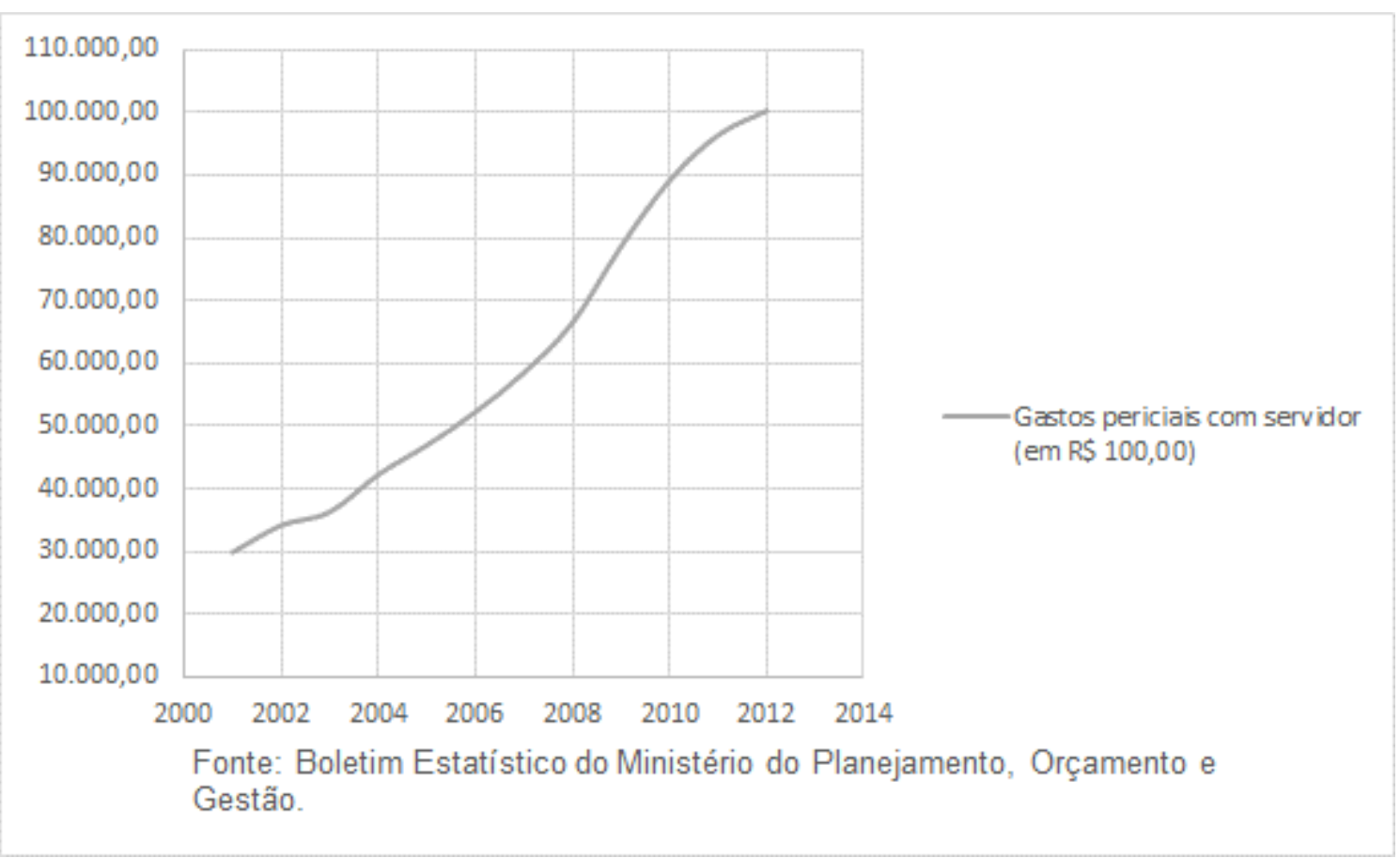


Segundo Johanson e Palme (2004), tanto o aumento no número de exames médicopericiais realizados, quanto o aumento nos gastos com perícias médicas em trabalhadores, desestimulariam o uso do benefício nos dois regimes.

Outro fator redutor da concessão de benefícios é o número de benefícios cessados. Nesse caso, houve um ligeiro aumento no total de benefícios cessados entre 2001 e 2012. Já em relação apenas à cessão por fraude, ocorreu uma queda em 2003, antes da emenda, apresentando uma recuperação somente a partir de 2005. Tais variações são apresentadas no Gráfico 10.

\section{Gráfico 10 - Evolução dos Benefícios Cessados e dos Benefícios Cessados por Fraude no RGPS*}

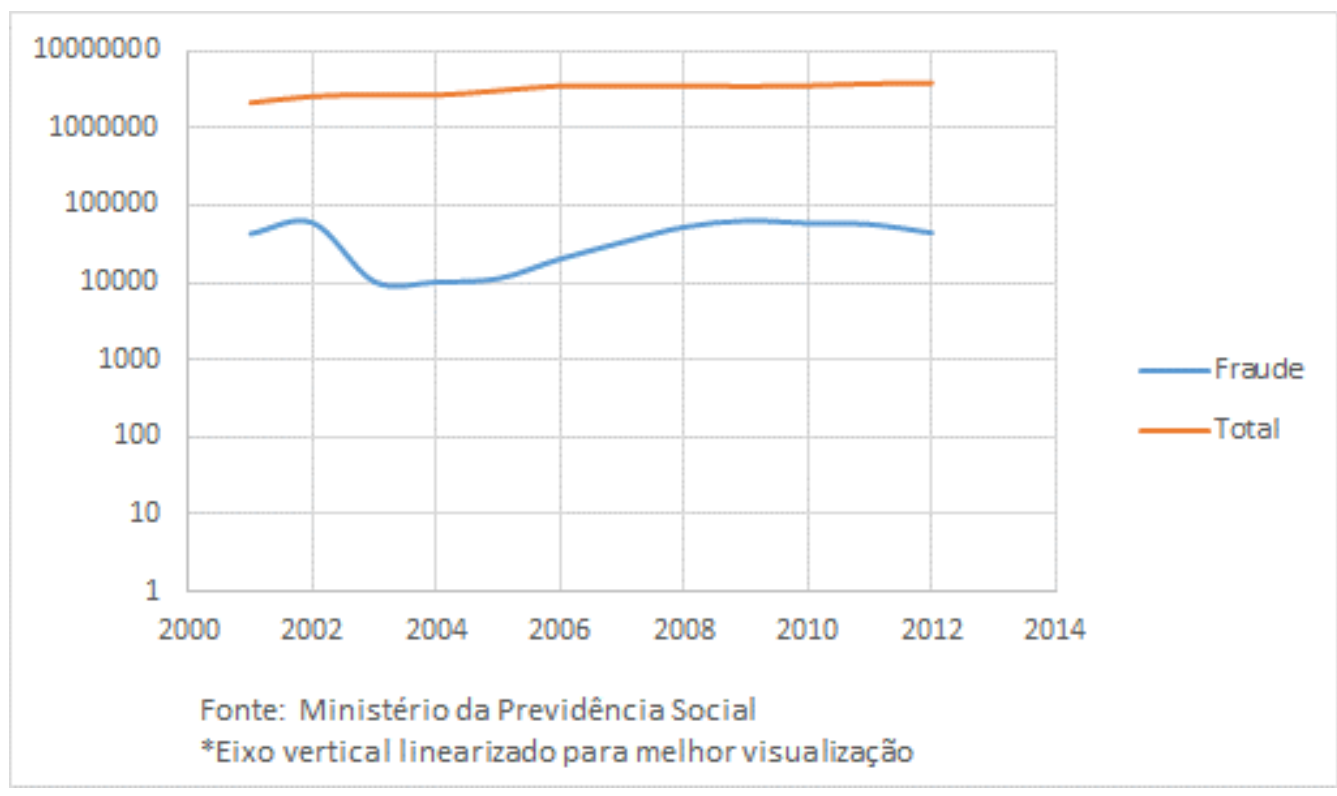

Os dados revelam uma ambiguidade na tendência relativa ao número de aposentadorias por invalidez. Enquanto a alta na quantidade de exames no RPPS, ou os maiores gastos com ele no RGPS, é redutora, a baixa na identificação de fraudes exerceria uma pressão de alta. Apesar disso, é possível haver um aumento no trabalho pericial sem a correspondente alta no número de cessão de benefícios por fraude, haja vista a ação preventiva exercida pela perícia, evitando a própria concessão do benefício. 


\section{III.4 Escolha do grupo de controle}

Diante dessas ambiguidades, torna-se importante a utilização de um parâmetro para melhorar a visualização apenas do impacto da mudança normativa. Para isolar essa influência dos fatores conjunturais, pode-se usar como referência os trabalhadores ligados ao RGPS.

Cabe ressaltar que, no Brasil, há diferenças significativas nos indicadores sociais entre os servidores públicos e os trabalhadores da iniciativa privada. Entre elas, destacam-se a maior renda e a maior escolaridade no setor público. Em 2005, a renda no serviço público foi $72 \%$ superior, e os servidores com mais de 11 anos de estudo representavam $73 \%$ da força de trabalho contra apenas $34 \%$ na iniciativa privada (Braga et al., 2008).

Para entender como isso poderia prejudicar uma comparação entre os dois grupos, pode-se observar o comportamento da procura por atendimento à saúde, o que está associado à invalidez. Segundo Kassouf (2005), as variáveis importantes na demanda por serviços médicos são: a infraestrutura do domicílio, características individuais, renda familiar e, na área urbana, o nível de escolaridade. No caso de maior escolaridade, identificou-se queda no uso de atendimento médico. Tal resultado pode ser associado a maiores cuidados com prevenção de doenças.

Consoante à utilização do benefício, um estudo na Dinamarca entre 1998 e 2002 (GUPTA et al., 2012), revelou uma relação inversa entre anos de estudo e incapacidade temporária para o trabalho de $38 \%$ para homens e $16 \%$ para mulheres. Identificaram também uma relação positiva entre essa incapacidade e trabalhos considerados "pesados", de 26\% e 37\% para homens e mulheres, respectivamente. Entretanto, não se chegou a resultados conclusivos sobre os efeitos dessas variáveis sobre o número de aposentadorias por invalidez.

O comportamento dos trabalhadores ligados ao RGPS será utilizado como uma espécie de variável de controle, pois absorveriam praticamente todas as demais variações, menos o impacto de uma alteração de regras, exclusiva do RPPS. Porém, para diminuir as diferenças entre os dois grupos, serão utilizados apenas os trabalhadores do RGPS na Zona Urbana. No próximo capítulo, o caso da aposentadoria por invalidez no Brasil será analisado diante das alterações restritivas em 2003. 


\section{CAPÍTULO IV - O COMPORTAMENTA DA APOSENTADORIA POR INVALIDEZ NO BRASIL SOB EFEITOS DA EMENDA À CONSTINUIÇÃO No 41 DE 2003}

Segundo o Anuário Estatístico da Previdência Social (AEPS), o benefício pode "ser classificado em benefício programável e benefício de risco; o primeiro designa a aposentadoria e o segundo refere-se à invalidez, pensão e auxílios de modo geral (auxíliodoença, auxílio reclusão, etc.) " (MPS, 2009).

Conforme dito, o benefício programado, composto por aposentadoria integral e proporcional, depende de uma decisão de aposentar do participante. Já o benefício de risco não deveria depender da vontade do beneficiado. $\mathrm{O}$ evento gerador desse tipo de benefício se dá de forma aleatória, como um acidente ou o desenvolvimento de doenças incapacitantes.

Portanto, alterações nas normas não deveriam causar mudanças significativas na quantidade de aposentadorias, mesmo quando reduzem os valores a serem auferidos nos casos de incapacitação para o trabalho.

Para testar essa hipótese, deve-se avaliar como os agentes responderam à alteração feita na regra da aposentadoria em 2004, mensurando, caso haja alguma mudança, o quantitativo de servidores públicos que evitaram a aposentadoria por invalidez devido à nova regra.

\section{IV.1 Descrição dos dados}

Serão utilizadas neste trabalho quatro séries de dados, de janeiro de 2001 a dezembro de $2012^{9}$, quais sejam: o número de aposentadorias por invalidez dos servidores civis da união vinculados ao RPPS, o número de aposentadoria por invalidez dos trabalhadores vinculados ao RGPS, o número de acidentes de trabalho total na administração pública ${ }^{10}$ e o número de acidentes dos demais trabalhadores.

A descrição das séries encontra-se na Tabela 1.

\footnotetext{
${ }^{9}$ Embora houvesse dados de 2013 para o RPPS, durante a elaboração deste estudo os dados referentes ao RGPS ainda estavam indisponíveis.

${ }^{10}$ Código CNAE, o que inclui os militares, ao contrário dos dados previdenciários anteriores. Para obter a série mês a mês, o percentual anual de participação do código selecionado foi encontrado, servindo como ponderação da série por atividade total, a única apresentada mensalmente.
} 
Tabela 1 - Descrição das Variáveis

\begin{tabular}{lrrrrr}
\hline \multicolumn{1}{c}{ Variáveis } & $\begin{array}{c}\text { № de } \\
\text { observações }\end{array}$ & Média & $\begin{array}{l}\text { Desvio } \\
\text { Padrão }\end{array}$ & Min & Max \\
\hline $\begin{array}{l}\text { № de aposentadoria por } \\
\text { invalidez no RGPS }\end{array}$ & 144 & 13.267 & 3.563 & 3.442 & 25.331 \\
\hline $\begin{array}{l}\text { № de acidentes de trabalho dos } \\
\text { demais trabalhadores }\end{array}$ & 144 & 46.543 & 12.550 & 23.902 & 72.281 \\
\hline $\begin{array}{l}\text { № de aposentadoria por } \\
\text { invalidez no RPPS }\end{array}$ & 144 & 1.155 & 5.153 & 16 & 367 \\
\hline $\begin{array}{l}\text { № de acidentes de trabalho na } \\
\text { administração pública }\end{array}$ & 144 & 1.334 & 537 & 499 & 2.236 \\
\hline
\end{tabular}

\section{IV.2 Análise Gráfica}

Após a vigência da EC 41/03, decresce sensivelmente o número de aposentadoria por invalidez. Há uma quebra a partir de 2004, e os níveis vistos desde 1998 apresentam uma queda acentuada (vide Gráfico 11).

\section{Gráfico 11- Número anual de aposentadorias por invalidez no RPPS antes e depois da EC n ${ }^{\circ}$ 43/2003}

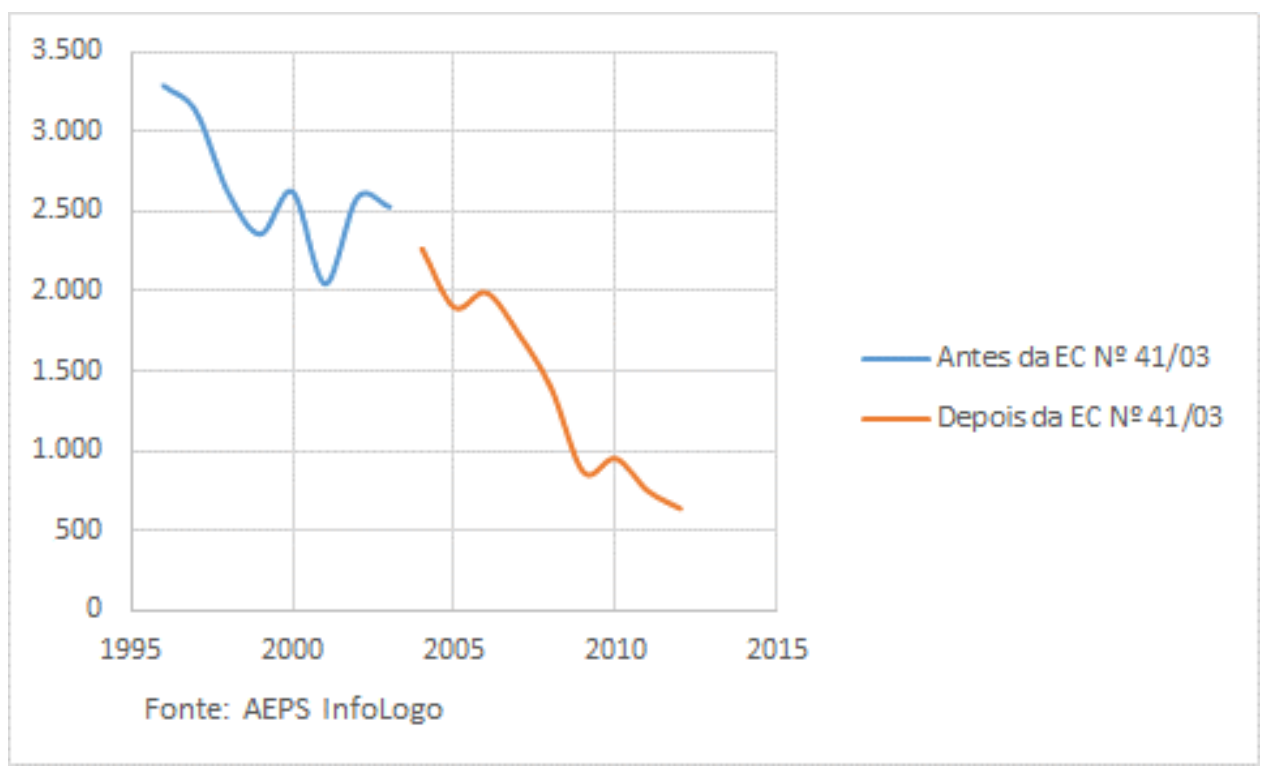

A ruptura em 2004 não está evidenciada em termos percentuais, conforme mostrado no Gráfico 12, devido à antecipação explicada no capítulo anterior. Os servidores elegíveis à aposentadoria programada em 2003 não diluíram suas saídas ao longo dos anos, como habitual, mas as concentraram em 2003: o número de aposentadorias voluntárias (integrais e 
proporcional) passou de 6.940 em 2002 para 14.847 em 2003, significando um aumento de $114 \%$ em relação ao ano anterior. Por conseguinte, diminuiu o número de aposentadorias voluntárias relativamente aos demais tipos de aposentadoria nos anos subsequentes. Tal fenômeno impactou os próximos cinco anos, até 2008. A partir disso, as consequências também são percebidas em termos percentuais.

\section{Gráfico 12 - Evolução anual da participação percentual dos diferentes tipos de aposentadorias no RPPS}

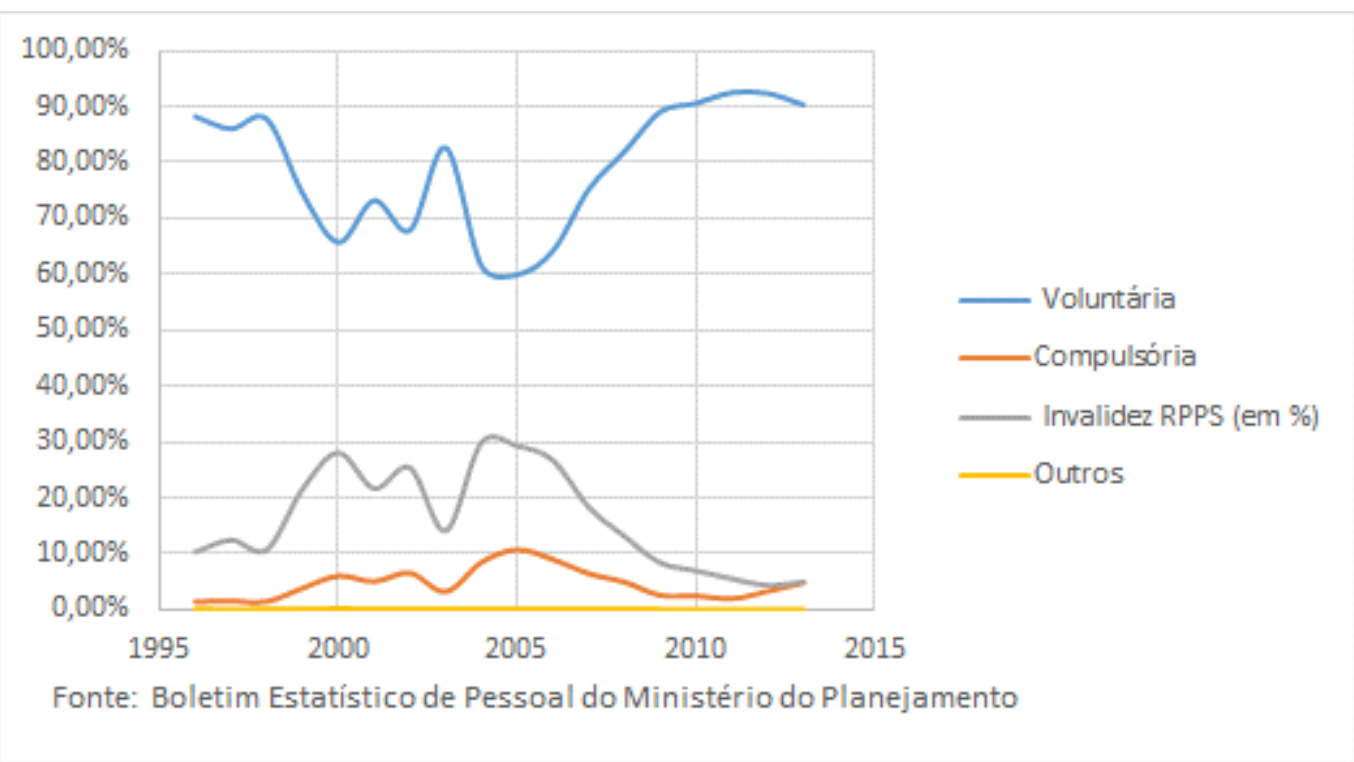

No RGPS, há mais variação nos dados e não se observa uma ruptura em 2004 (Gráfico 13). Apesar de também haver uma tendência linear de crescimento no primeiro período, entre 2001 e 2003, e uma tendência linear de alta entre 2004 e 2012, nesse caso parte-se de um referencial menor no primeiro período. O resultando ao longo de todo o tempo, entre 2001 e 2012, é de uma pequena alta. 


\section{Gráfico 13- Número mensal de Aposentadorias por Invalidez no RGPS}

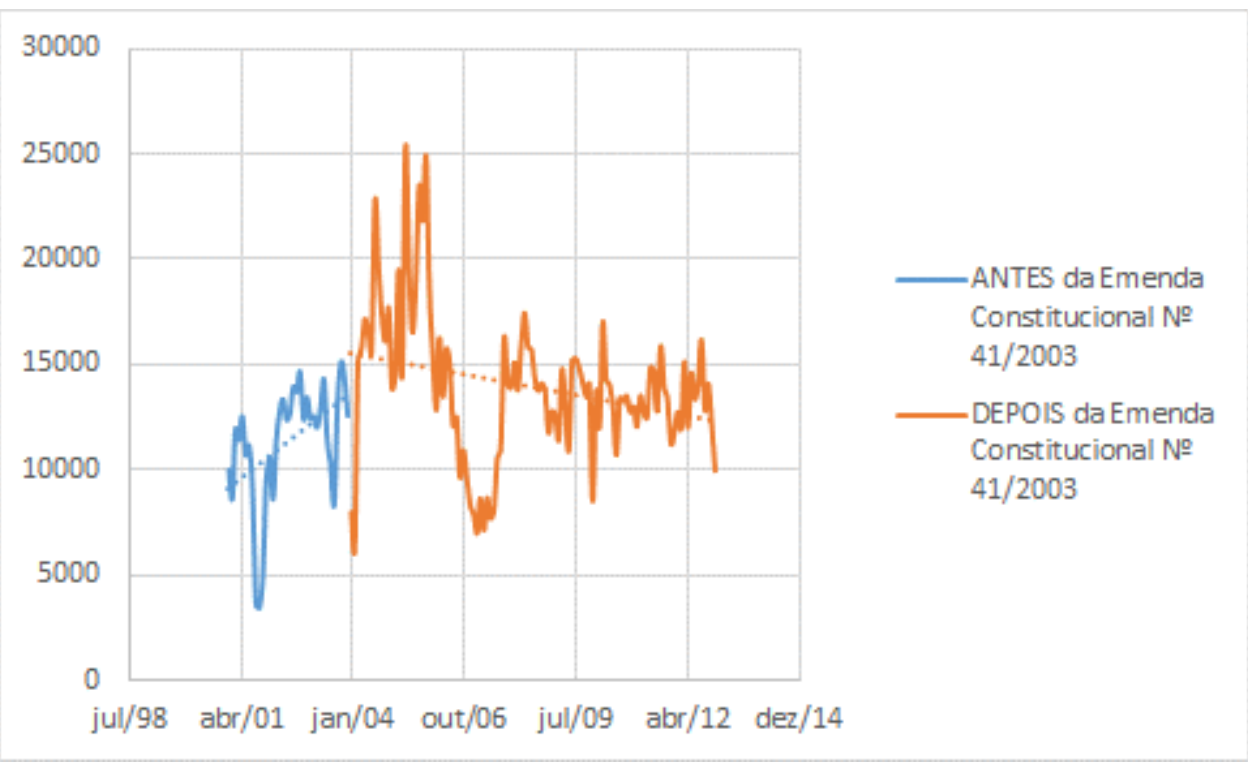

\section{IV.2.1 Análises Gráficas da Invalidez e Acidentes de Trabalho}

Conforme visto no capítulo anterior, as condições de saúde ou o número de exames periciais podem impactar a aposentadoria por invalidez. Porém, apresentaram tendências ambíguas no Brasil, principalmente se restritos a servidores. Por isso, é importante estudar outro fator com impacto nos riscos do trabalho, capaz de diminuir o número de acidentes laborais ${ }^{11}$. Tal fato poderia diminuir a incidência de trabalhadores inválidos por acidente.

Cabe informar que somente os pequenos acidentes, causadores de simples assistência médica e incapacidade temporária, são computados na mesma data. Os acidentes cuja consequência, no ano, foi incapacidade permanente, é computado na data de início do benefício.

Conforme mostra o Gráfico 14, há um aumento no número de acidentes de trabalho em ambos os regimes. Inclusive, o aumento é maior entre os servidores públicos. Tal fato afetaria positivamente o número de invalidez registrado. Porém, essa tendência só foi identificada no RGPS.

\footnotetext{
${ }^{11} \mathrm{O}$ número de acidentes é baseado na Comunicação de acidente de trabalho (CAT), a ser preenchida em até 48 horas, e no Sistema Único de Benefícios (SUB).
} 


\section{Gráfico 14- Evolução Mensal do Número de Acidentes de Trabalho}

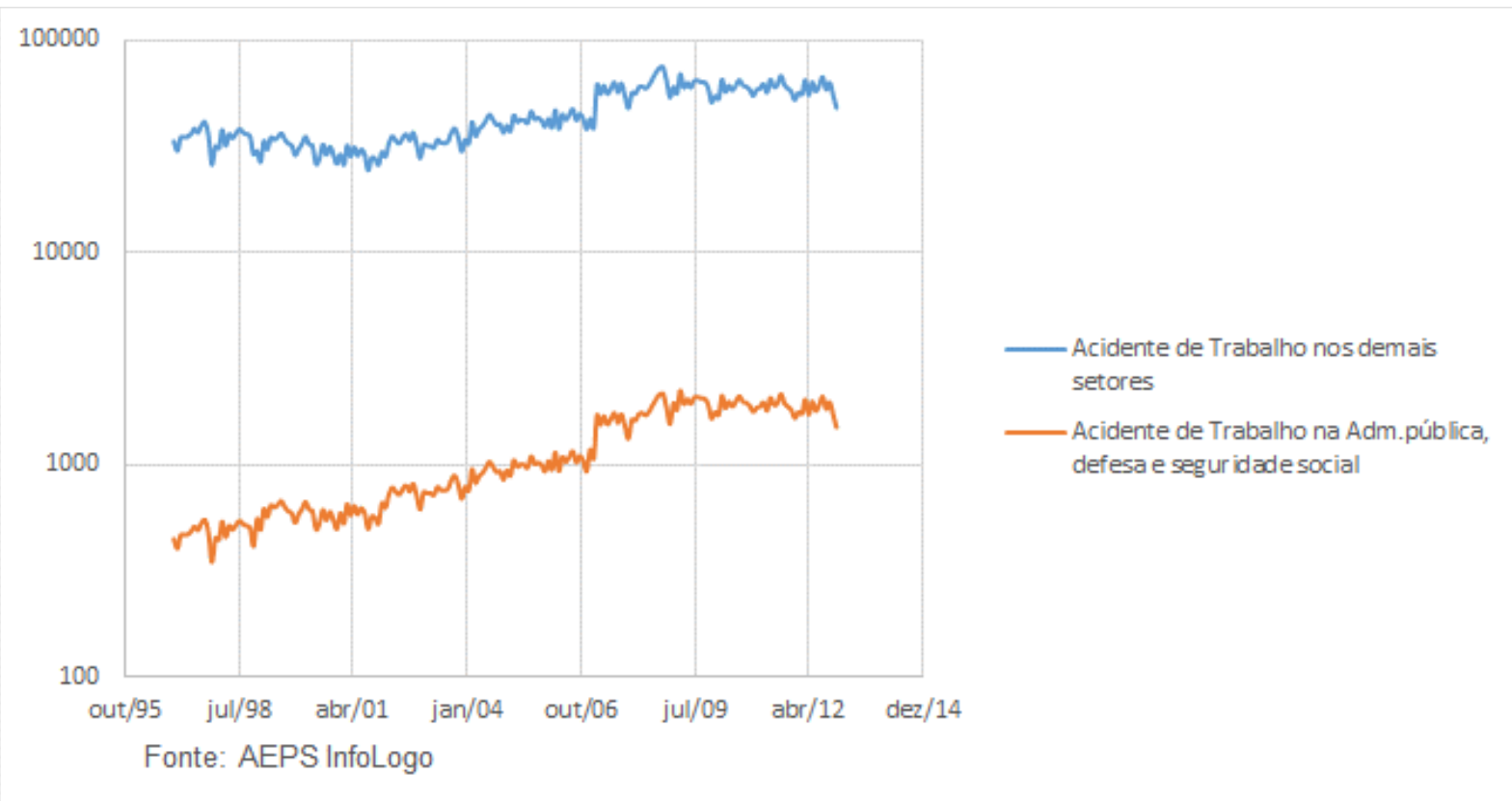

Outra forma de ver isso, e tentarmos achar outro motivo senão o da mudança na legislação em 2004 é o de avaliarmos o comportamento da aposentadoria por invalidez no RGPS, administrada pelo INSS, haja vista não ter sofrido desincentivo a esse tipo de benefício, ou seja, seria de se esperar, caso a queda na aposentadoria por invalidez fosse decorrente de outro fenômeno, um comportamento semelhante no RGPS.

O Gráfico 15 mostra o comportamento da aposentadoria por invalidez ao longo dos anos no RGPS. 
Gráfico 15- Número de Aposentadorias por Invalidez no RGPS por Zona Rural e Zona Urbana

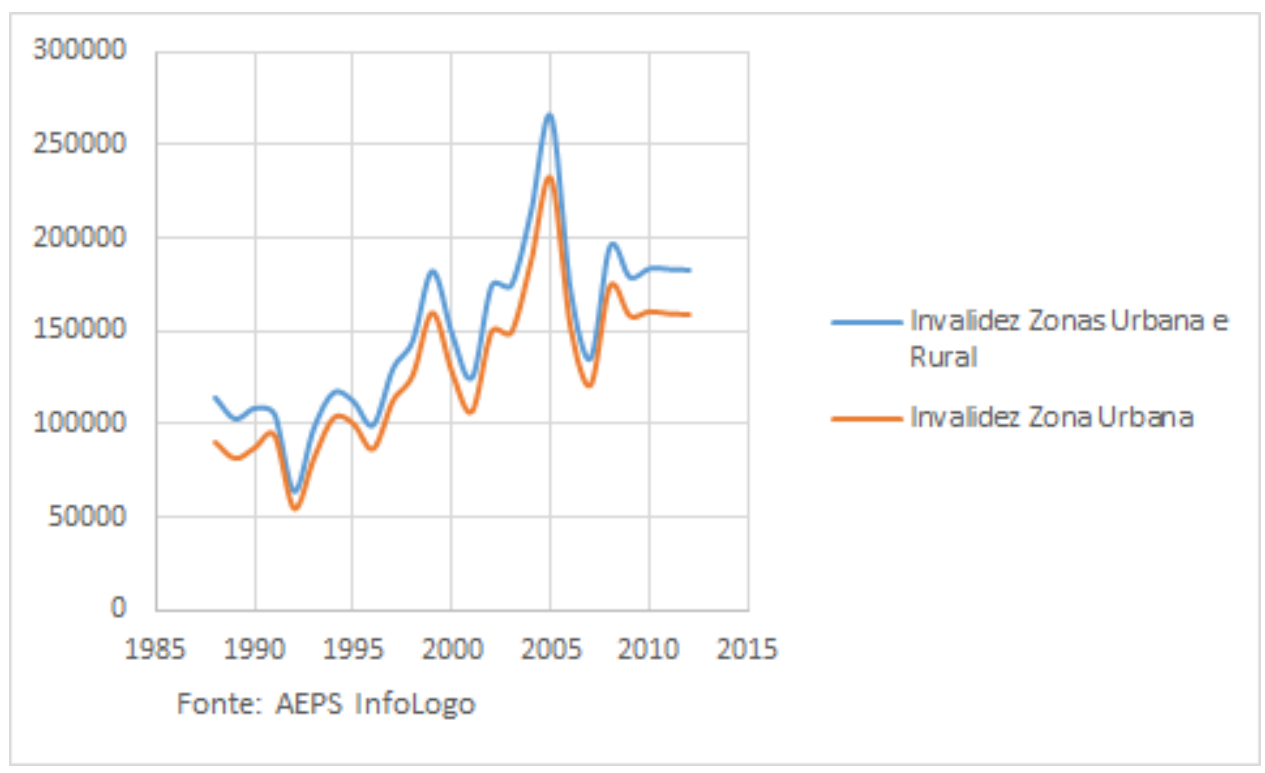

As séries apresentam maiores variações, tanto para o conjunto de trabalhadores urbanos e rurais quanto somente para os trabalhadores urbanos. Como o trabalho urbano assemelha-se mais ao praticado no serviço público, esse será o perfil do RGPS utilizado. O Gráfico 16 mostra o comportamento da aposentadoria por invalidez em termos percentuais.

\section{Gráfico 16- Percentual de Aposentadoria por Invalidez no RGPS por Zona Rural e Zona Urbana}

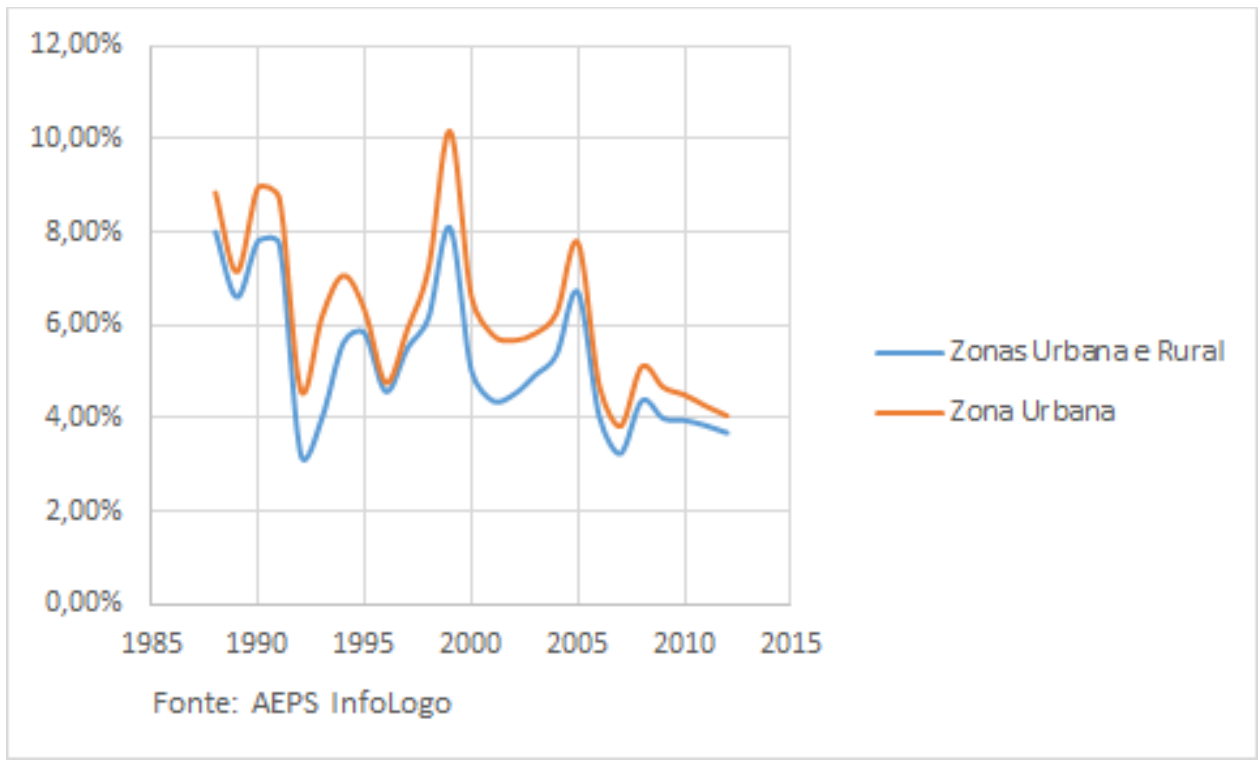

Nota-se mais claramente o efeito aleatório. Com exceção do ano 2000, as tendências são semelhantes entre as duas classes do RGPS, urbana e total. Entre 2001 e 2012, houve uma 
pequena queda relativa da aposentadoria por invalidez na Zona Urbana, passando de 5,79\% para $4,05 \%^{12}$.

\section{IV.2.2 Análises do Quantitativo de Aposentadoria por Invalidez}

Para melhor ilustrar a diferença entre o RPPS, que teve uma alteração na lei que "desestimulou" a aposentadoria por invalidez, e o RGPS, elabora-se o Gráfico 17. Nele, os dados aparecem logaritmizado. Isso permite melhorar a visualização das tendências diante da diferença na magnitude de aposentadorias entre os dois grupos.

\section{Gráfico 17- Número de Aposentadorias por Invalidez logaritmizado no RGPS e no RPPS de 1996 a 2012}

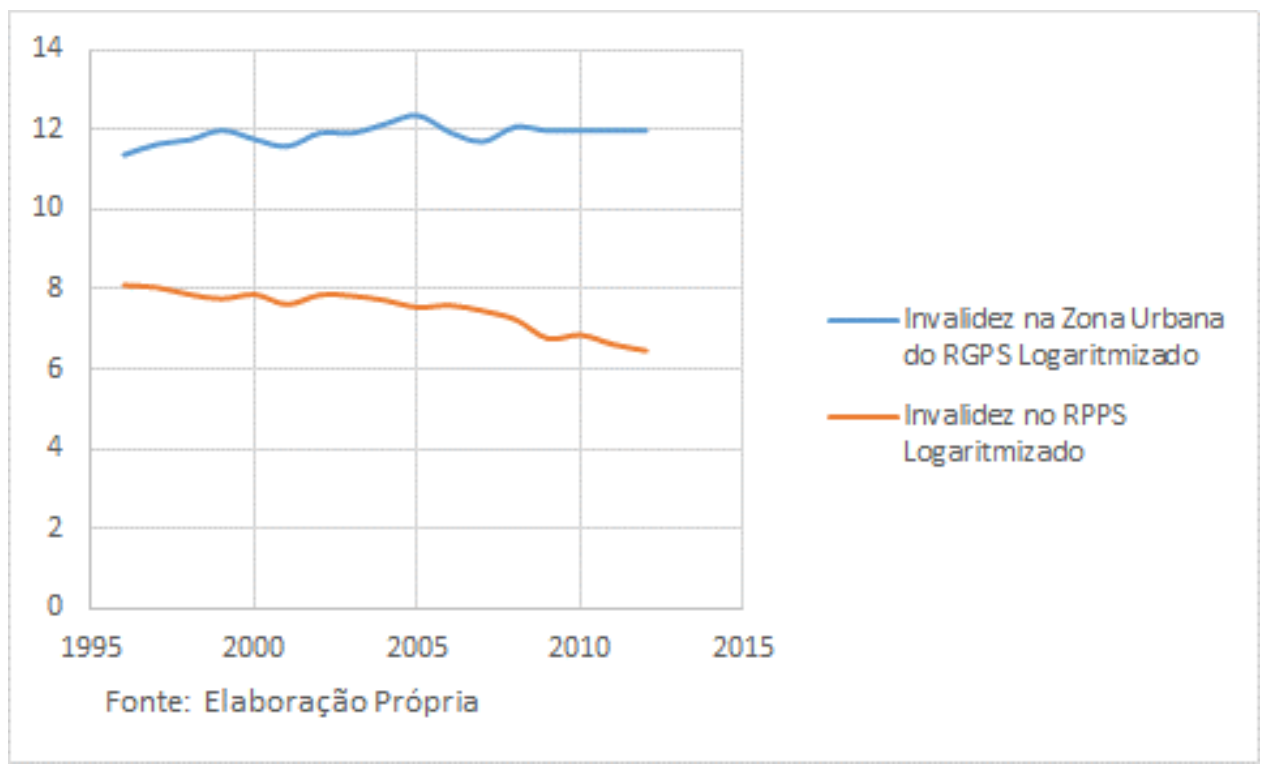

Tendo em vista o grande número de aposentadoria voluntária em 2003, em decorrência da antecipação provocada por normas mais restritivas da EC 41/03, os dados por quantidade refletem melhor a tendência da utilização do benefício de invalidez no RPPS. Diante da diferença em termos absolutos entre os segurados do RGPS e do RPPS, usou-se logaritmos dos dados para melhor visualização. Ao utilizar o mesmo critério, mas com o corte em 2003, obtêm-se o Gráfico 18. Nele, a divergência na tendência desse tipo de aposentadoria entre os dois regimes é evidenciada.

\footnotetext{
12 Realmente, ao observar as variáveis potencialmente explanatórias da quantidade de aposentadoria por invalidez no RGPS, como número de internações, gasto em saúde ou identificação de fraude, não se percebe alterações significativas. Entretanto, por ser a variável de controle, todos esses fatores conjunturais serão incorporados e úteis à análise em questão.
} 


\section{Gráfico 18- Número de Aposentadorias por Invalidez logaritmizado no RGPS e no RPPS de 2003 a 2012}

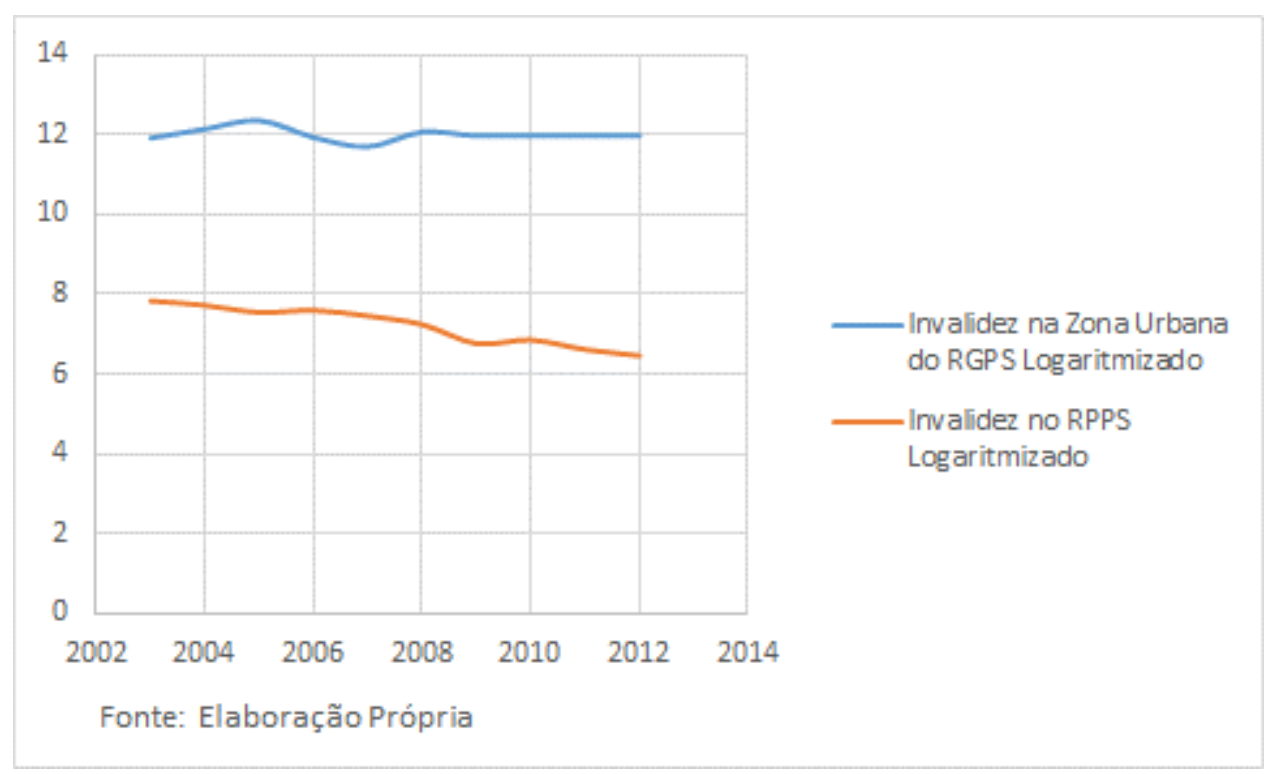

Enquanto o indicador no RGPS mantém-se praticamente constante, percebe-se uma queda acentuada no RPPS, fortalecendo a ideia dessa queda ter como origem as novas regras de aposentadoria dos servidores.

Cabe lembrar também que não será usada uma série para os trabalhadores vinculados ao RPC porque já estão incluídos no grupo do RGPS.

\section{IV.3 Mensuração dos Impactos}

Os métodos de avaliação de impacto podem ser divididos entre experimental e nãoexperimental. No primeiro método, compara-se os participantes e os não-participantes de um determinado tratamento com uso de amostras selecionadas aleatoriamente (FOGUEL, 2012). O método não-experimental tenta reproduzir esse resultado lançando mão de diversos métodos estatísticos. Entre eles destaca-se o Método de Diferenças em Diferenças (DD) ou difference in diferences que é um método simples que se baseia na observação de dois grupos em dois momentos diferentes. Um dos grupos considerados é exposto ao tratamento no segundo período, mas não no primeiro, enquanto o segundo grupo não é exposto em momento algum. Então, a variação ocorrida no grupo de controle é excluída do grupo estudado na tentativa de excluir os efeitos causados por outras tendências na conjuntura econômica no período analisado (WOOLDRIDGE, 2007).

Com o uso dessa abordagem, os problemas relacionados com omissões de variáveis, como impactos causados por alterações em outras leis e nas condições do mercado de trabalho, ou 
com medições incorretas, como mudanças nos métodos de pesquisa, ou ainda nas tendências dos resultados, como o comportamento da conjuntura econômica, são reduzidos ou até eliminados (MEYER, 1995).

Para mensurar os impactos de acordo com o método proposto, deve-se calcular o Estimador de DD.

\section{IV.3.1 Estimador de DD $\left(\mathbf{E}_{d d}\right)$}

O Estimador de Diferenças em Diferenças (Edd) se baseia no cálculo de uma dupla subtração. A primeira é a diferença entre a média da variável de resultado entre os períodos anterior e posterior ao tratamento, tanto para os participantes quanto para os não-participantes. A segunda é a diferença desse resultado entre os dois grupos. O cálculo do estimador é demonstrado na Tabela 2.

Tabela 2- Estimador de Diferenças em Diferenças $\left(\mathbf{E}_{\mathbf{d d}}\right)$

\begin{tabular}{lccc}
\hline & Grupo Tratado & Grupo Não-Tratado & Diferença \\
\hline Antes & $\mathrm{T}^{\mathrm{a}}$ & $\mathrm{N}^{\mathrm{a}}$ & $\mathrm{T}^{\mathrm{a}}-\mathrm{N}^{\mathrm{a}}$ \\
\hline Depois & $\mathrm{T}^{\mathrm{d}}$ & $\mathrm{N}^{\mathrm{d}}$ & $\mathrm{T}^{\mathrm{d}}-\mathbf{N}^{\mathrm{d}}$ \\
\hline Diferença & $\mathrm{T}^{\mathrm{d}}-\mathrm{T}^{\mathrm{a}}$ & $\mathrm{N}^{\mathrm{d}}-\mathrm{N}^{\mathrm{a}}$ & $\mathbf{E}_{\mathrm{dd}}=\left(\mathbf{T}^{\mathrm{a}}-\mathbf{T}^{\mathrm{a}}\right)-\left(\mathbf{N}^{\mathrm{d}}-\mathbf{N}^{\mathrm{a}}\right)=\left(\mathbf{T}^{\mathrm{d}}-\mathbf{N}^{\mathrm{d}}\right)-\left(\mathbf{T}^{\mathrm{a}}-\mathbf{N}^{\mathrm{a}}\right)$ \\
\hline
\end{tabular}

No presente estudo, os grupos estudados serão os dos trabalhadores vinculados ao RPPS, como o grupo que sofreu o tratamento (T), e o grupo dos participantes do RGPS, como o grupo de controle $(\mathrm{N})$. As alterações de regras da EC 41/03 é considerada o tratamento. Cabe lembrar que as alterações não atingiram os assistidos pelo RGPS, ao contrário de outras mudanças geopolíticas, sendo o comportamento do número de aposentadoria por invalidez nesse grupo o esperado para o grupo analisado caso não houvesse alterações externas. Utilizando essa metodologia nos dados sintetizados na Tabela 1, obtém-se o $\mathrm{E}_{\mathrm{DD}}$, exposto na Tabela 3.

Tabela 3- Média e Desvio Padrão de aposentadorias por invalidez por grupo e período

\begin{tabular}{|c|c|c|c|}
\hline & RPPS & RGPS & Diferença \\
\hline Antes & $160(54)$ & $11.284(2.841)$ & -11.124 \\
\hline Depois & $101(41)$ & $13.929(3.545)$ & -13.828 \\
\hline Diferença & -59 & 2.645 & -2.704 \\
\hline
\end{tabular}

Nota: Desvio Padrão entre parênteses

O resultado mostra uma queda significativa no total de aposentadorias por invalidez de 2.704 após a EC 41/03. O estimador revela que o tratamento alterou a tendência e não só 
impediu o crescimento da variável observada como a diminuiu. Esse efeito é ilustrado pela seta vermelha no Gráfico 19. Nesse gráfico, a linha tracejada seria a tendência de alta esperada caso não houvesse interferência normativa. As linhas azul e cinza são os comportamentos observados no RGPS e no RPPS respectivamente.

\section{Gráfico 19- Número de aposentadorias por invalidez logaritmizado dos tratados e não tratados, antes e depois do tratamento}

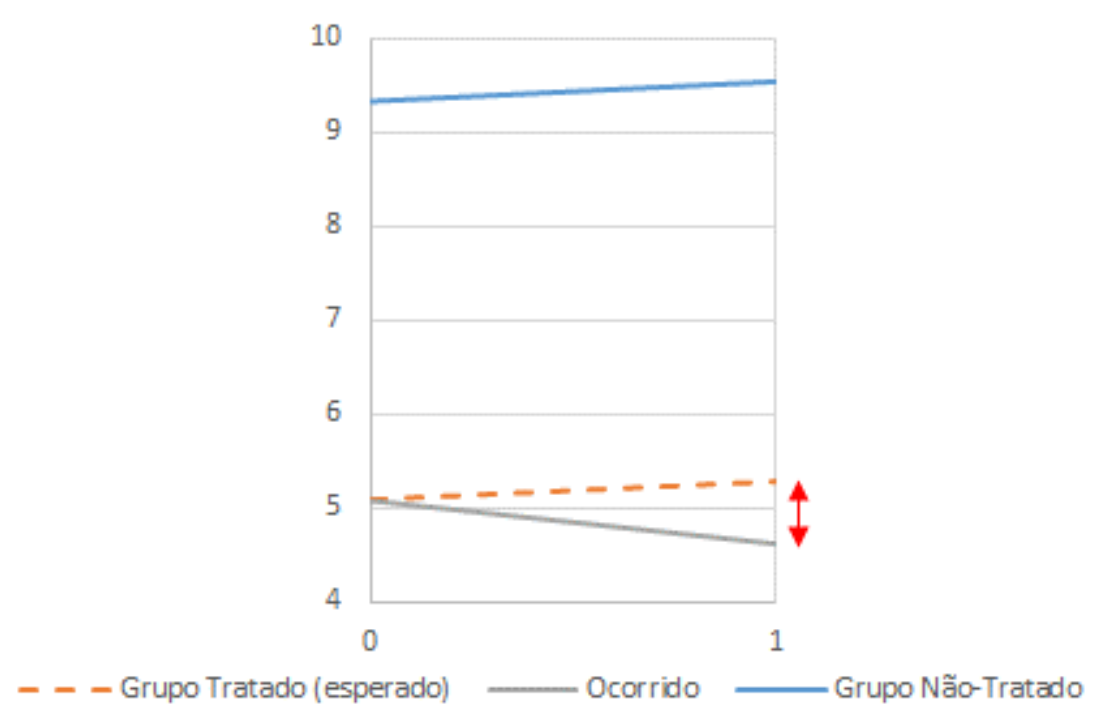

\section{IV.3.2 $\mathbf{E}_{\mathbf{d d}}-$ Modelo com regressão linear}

Segundo Foguel (2012), pode-se empregar uma regressão linear usada em modelos de dados de painel para verificar como o método de DD controla a influência das características não observáveis constantes no tempo. Para isso, estima-se uma regressão pelo método dos Mínimos Quadrados Ordinários Agrupados (MQA) ${ }^{13}$ a partir do modelo econométrico dado pela equação 1 .

$N A_{i t}=\beta_{0}+\beta_{1} R P P_{i t}+\beta_{2} D E P O I S_{i t}+\beta_{3}\left(R P P_{i t} \times D E P O I S_{i t}\right)+\mathrm{u}_{i t}$

Na qual $\mathrm{i}=\mathrm{RG}$ ou RP denota o regime de aposentadoria do trabalhador representativo (RGPS ou RPPS) e $\mathrm{t}=1, \ldots, 144$ (janeiro de 2001 a dezembro de 2012), o período de tempo (mês), $N A_{i t}$ é o número de aposentados por invalidez no regime $i$ no tempo $t$. Por exemplo, $N A_{R G, 4}=11.422$ e $N A_{R P, 13}=223$, ou seja, o número de aposentadorias por invalidez em abril

${ }^{13}$ Pooled OLS. 
de 2001 no RGPS e o número de aposentadorias por invalidez em janeiro de 2002 no RPPS, respectivamente; RPP é uma variável dummy igual a 1 para o RPPS e 0 caso contrário; DEPOIS também é uma variável dummy, sendo 1 para períodos a partir de janeiro de 2004 $(\mathrm{t}=37, \ldots, 144)$ e 0 para períodos anteriores $(\mathrm{t}=1, \ldots, 36)$. Portanto, o estimador $\beta_{2}$ seria a primeira diferença.

Por último, $R P P_{i t} \times D E P O I S_{i t}$ é uma variável formada pela interação das outras duas variáveis dummies. Dessa forma, é igual a 1 quando as outras duas variáveis são assumem o valor 1 ou seja quando trata-se do RPPS e também tenha ocorrido posterior à vigência da nova regra; e assume o valor zero, caso contrário. Com isso, espera-se obter o $E_{d d}$, representado pelo $\beta_{3}$.

Por fim, $\mathrm{u}_{i t}$ é o erro estocástico.

\section{IV.3.3 Estimativas}

A regressão pelo método dos MQA, com erros-padrão robustos de Huber-White ${ }^{14}$, obtém os resultados expostos na Tabela 4.

Tabela 4 - Resultados da Regressão MQA com o Quantitativo de Aposentadorias

\begin{tabular}{lrrr}
\hline \multicolumn{1}{c}{ Efeito } & Estimativa & $\begin{array}{r}\text { Desvio } \\
\text { Padrão }\end{array}$ & Valor t \\
\hline RPP & -11.123 & 470 & $-23,65$ \\
DEPOIS & 2.645 & 581 & 4,55 \\
RPPDEPOIS & -2.705 & 581 & $-4,65$ \\
INTERCEPTO & 11.284 & 470 & 24,0 \\
R $^{2}$ AJUSTADO & 0,8860 & & \\
F & 736 & (3 e 284 g.l.) \\
ERRO QUADRÁTICO MÉDIO & 2.394 & & \\
\hline
\end{tabular}

Obteve-se o modelo estimado da fórmula (2):

$\widehat{N A}_{i t}=11.284-11.123 R P P_{i t}+2.645 D_{E P O I S}-2.705 R P P_{i t} \times D E P O I S_{i t}$

\footnotetext{
${ }^{14}$ Para uma melhor aferição, a fim de reduzir as influências de observações incomuns (grandes resíduos) será aplicada a função "robust" à função "regress" no software Stata 13.0. Em síntese, o critério consiste em minimizar a função $S_{\rho}(\beta)=\sum_{i=1}^{n} \rho\left(z_{i}\right)$ em que $z_{i}=\varepsilon_{i}(\beta)$, com $\rho(\mathrm{z})=\left\{\begin{array}{c}z^{2} / 2 \text { se }|z| \leq c \\ c\{|z|-c / 2\} \text { se }|z|>c .\end{array}\right.$
} 
Como esperado, o estimador "DEPOIS" apresentou sinal positivo, seguindo a tendência do RGPS, enquanto os sinais para o RPPS são negativos.

Constata-se novamente um aumento médio de $2.645\left(\beta_{2}\right)$ aposentadorias por invalidez no RGPS depois da lei. Sendo RPP $i t=1$ e também $\operatorname{RPP}_{i t} \times$ DEPOIS $_{i t}=1 \times 1=1$ nos casos de RPPS depois da lei, o número de aposentadoria por invalidez após 2003 pode ser dado por $\beta_{2}$ $+\beta_{3}$. Desta forma, excluindo os efeitos da variável de controle, verifica-se uma queda média mensal de 59 servidores aposentados por invalidez devido à lei (2.645 - 2.705).

Ainda assim, esse valor pode ser considerado subestimado, tendo em vista que houve redução diante de uma perspectiva de alta, apresentando como efeito final a queda identificada pelo estimador de diferenças em diferenças $\left(\beta_{3}\right)$ de 2.704 servidores.

Em relação à confiabilidade do modelo, cabe observar que o p-valor associado a $\mathrm{F}$ (736) é da ordem de 0.0000 , então o modelo é globalmente significante com a rejeição da hipótese nula $\beta_{1}=\beta_{2}=\beta_{3}=0$. Sendo o valor de $P$, para todas as variáveis, zero $(0,000)$, todos os parâmetros são marginalmente significativos. Também, pode-se concluir que $88,60 \%$ da variabilidade da aposentadoria por invalidez é explicada pelas variáveis usadas.

\section{IV.3.4 Estimativas com Valor Logaritmizado}

Como a magnitude do número de aposentadoria entre os dois grupos é bem diferente, opta-se por utilizar os valores da série número de aposentados por invalidez logaritmizado: LNA. Obtém-se as estimativas à Tabela 5.

Tabela 5 - Resultados da Regressão MQA com os valores de Aposentadorias Logaritmizado

\begin{tabular}{lrrr}
\hline \multicolumn{1}{c}{ Efeito } & Estimativa & \multicolumn{1}{c}{$\begin{array}{c}\text { Desvio } \\
\text { Padrão }\end{array}$} & Valor t \\
\hline RPP & $-4,41$ & 0,08 & -57 \\
DEPOIS & 0,20 & 0,06 & 3,16 \\
RPPDEPOIS & $-0,71$ & 0,09 & $-7,69$ \\
INTERCEPTO & 9,44 & 0,06 & 165 \\
R $^{2}$ & 0,98 & & \\
F & 4835 & $(3$ e 284 g.l. $)$ & \\
ERRO QUADRÁTICO MÉDIO & 0,36 & & \\
\hline
\end{tabular}

Todos os parâmetros continuam marginalmente significativos. De acordo com MEYER (1995, p. 155), a obtenção de efeitos marginais no modelo logaritmizado é afastada pela significância dos estimadores. Nesse caso, os estimadores são as variações de 
aposentadorias por invalidez no RGPS $\left(\beta_{2}\right)$ e no RPPS $\left(\beta_{3}\right)$, antes e depois da alteração na regra $^{15}$. O resultado é o modelo de regressão linear apresentado na fórmula (3):

$\widehat{\operatorname{logN}} A_{i t}=9,44-4,41 R P P_{i t}+0,20 D E P O I S_{i t}-0,71 \mathrm{RPP}_{i t} \mathrm{DEPOIS}_{i t}$

Constata-se um aumento médio de $20 \%\left(\beta_{2}\right)$ aposentadorias por invalidez no RGPS depois do efeito da lei, além da queda de $71 \%\left(\beta_{3}\right)$ no RPPS. Sendo $\mathrm{RPP}_{i t}=1$ e também $\mathrm{RPP}_{i t}$ $\times$ DEPOIS $_{i t}=1 \times 1=1$ nos casos de RPPS depois da lei, o número de aposentadoria por invalidez após 2003 pode ser dado por $\beta_{2}+\beta_{3}$. Desta forma, excluindo os efeitos da variável de controle, verifica-se uma queda média mensal de $51 \%$ em aposentadorias por invalidez devido à lei.

\section{IV.3.5 Estimativas com Número de Acidentes}

Para obter uma análise mais robusta, deve-se introduzir mais uma variável explicativa (WOOLDRIDGE, 2007). A inclusão da variável "número de acidentes" (setor público e privado) age como uma proxy para "causa de invalidez" e tenta ressaltar as aposentadorias por invalidez em decorrência de acidentes (positivo), separando-as das aposentadorias motivadas pela nova lei. Também, introduz-se $t^{16}$, uma variável tendência que busca captar elementos de longo prazo relacionados com a série de tempo, ou seja, as demais alterações naturais do número de invalidez sem relação com a mudança na norma. Conforme visto no Gráfico 14, o número de acidentes aumenta no período para os dois grupos. Portanto, a queda no número de aposentadorias por invalidez no setor público não pode ser associada a uma melhora nas condições de trabalho.

Como resultado das estimações ${ }^{17}$, obteve-se os dados organizados na Tabela 6.

\footnotetext{
${ }^{15} \mathrm{O}$ estimador da diferença entre os regimes RPPS e RGPS antes da lei, $\beta 1$, não é relevante neste item

${ }^{16} \mathbf{T}=1,2, \ldots, 144$ (número de observações).

${ }^{17}$ Novamente se utiliza a função "regress, robust" no software Stata 13.0, MQA.
} 


\begin{tabular}{lrrr}
\multicolumn{4}{c}{$\begin{array}{c}\text { Tabela 6- Resultados da Regressão MQA com os Valores de } \\
\text { Aposentadorias e Acidentes de Trabalho Logaritmizado }\end{array}$} \\
\hline \multicolumn{1}{c}{ Efeito } & Estimativa & \multicolumn{1}{c}{$\begin{array}{l}\text { Desvio } \\
\text { Padrão }\end{array}$} & Valor t \\
\hline NAC & 0,0000189 & $3,93 \mathrm{e}-06$ & 4,79 \\
RPP & $-3,689021$ & 0,150480 & $-24,52$ \\
DEPOIS & 0,3905268 & 0,089635 & 4,36 \\
RPPDEPOIS & $-0,353271$ & 0,114424 & $-3,09$ \\
T & $-0,007819$ & 0,000783 & $-9,98$ \\
INTERCEPTO & 8,848957 & 0,1361824 & 64,98 \\
R 2 AJUSTADO & 0,9839 & & \\
F & 3792 & $(5$ e 282 g.I.) & \\
ERRO QUADRÁTICO MÉDIO & 0,31273 & & \\
\hline
\end{tabular}

Obtém-se então o modelo de regressão linear da fórmula (4):

$$
\begin{gathered}
\widehat{\operatorname{logN}} A_{i t}=8,848957+0,0000189 \mathrm{NAC}_{\mathrm{it}}-3,689021 \mathrm{RPP}_{\mathrm{it}}+0,3905268 \mathrm{DEPOIS}_{\mathrm{it}}- \\
0,3532705 \mathrm{RPP}_{i t} \mathrm{DEPOIS}_{i t}-0,0078189 \mathrm{~T}_{\mathrm{it}}
\end{gathered}
$$

Segundo o resultado acima, o número de aposentadoria por invalidez no grupo que não sofreu os efeitos da lei elevou-se em 39,0\%. Então, ao excluir os efeitos da variável de controle, houve uma queda média mensal de 35,3\% nas aposentadorias por invalidez no RPPS devido à lei.

Portanto, ao analisar a regressão fica clara a significância da alteração na norma e do número de acidentes para explicar a aposentadoria por invalidez no serviço público. O resultado exposto permite concluir que o número de acidentes de trabalho afeta a invalidez, sendo significativo, mas sua variação diante das novas regras é próxima de zero, de apenas $0,002 \%$. Isso revela o caráter independente da variável em relação às reações dos agentes, conforme esperado diante da sua natureza aleatória.

\section{IV.3.6 Estimativas com intervenções aleatórias}

Uma forma de constatar se o comportamento da variável observada realmente foi em decorrência da norma, evitando tendências com autocorrelação, é a de usarmos anos aleatórios como o ano inicial (BERTRAND et al., 2002). Nesse caso, espera-se a não validação da hipótese inicial de causalidade entre a lei e a queda do número de aposentadorias.

Para isso, usa-se como início do impacto da nova regra os anos de 2008 (metade da série) e 2010 (invertendo antes para 9 anos e o depois para 3 anos). 
Tabela 7- Resultados da Regressão MQA para períodos iniciados em 2008 e 2010

\begin{tabular}{|c|c|c|c|c|c|c|}
\hline Efeito & \multicolumn{2}{|c|}{ Estimativa } & \multicolumn{2}{|c|}{ Desvio Padrão } & \multicolumn{2}{|l|}{ Valor $\mathrm{t}$} \\
\hline & 2008 & 2010 & 2008 & 2010 & 2008 & 2010 \\
\hline RPP & -15.456 & -14.987 & 591 & 440 & $-26,13$ & $-34,07$ \\
\hline DEPOIS & -926 & -95 & 670 & 12 & $-1,38$ & $-8,15$ \\
\hline RPPDEPOIS & 829 & 220 & 670 & 522 & 1,24 & 0,42 \\
\hline INTERCEPTO & 15641 & 15.147 & 591 & 439 & 26,45 & 34,45 \\
\hline $\mathrm{R}^{2}$ & \multicolumn{6}{|c|}{0,8767 e 0,8750} \\
\hline $\mathrm{F}$ & \multicolumn{6}{|c|}{957 e 1.386 (3 e 284 g.I.) } \\
\hline ERRO QUADRÁTICO MÉDIO & \multicolumn{6}{|c|}{2.843 e 2.862} \\
\hline
\end{tabular}

Nos dois casos, pode-se observar que o $\mathrm{E}_{\mathrm{dd}}\left(\beta_{3}\right)$ passou a ser positivo, assumindo valores de 829 e 220.

Em relação à confiabilidade do modelo, cabe observar que o p-valor associado a $\mathrm{F}$ (957) e a F (1.385) é da ordem de 0.0000 , então o modelo seria globalmente significante com a rejeição da hipótese nula $\beta_{1}=\beta_{2}=\beta_{3}=0$. Entretanto, o valor de $\mathrm{P}$ passou de zero para $0,217 \mathrm{e}$ 0,673 para variável RPPDEPOIS, para 2008 e 2010 respectivamente. Também, elevou-se para 0,128 na variável DEPOIS para 2008. Assim, os parâmetros não mais seriam marginalmente significativos a $5 \%$.

\section{IV.4 Avaliação do Resultado}

A mudança de regras significou uma queda acentuada no número de aposentadorias. Tal queda pode ser classificada como uma diminuição do risco moral do agente, pois ao se deparar com uma redução no seu poder aquisitivo, não solicita a aposentaria.

Dessa situação, pode-se levantar duas hipóteses: parte dos servidores anteriormente se aposentava indevidamente, isto é, mesmo tendo condições de continuar a trabalhar, ou atualmente uma parcela deles faz um sacrifício, ao permanecer no serviço mesmo incapaz, para não empobrecer.

Para responder isso, deve-se verificar o comportamento da aposentadoria por invalidez nos dois regimes para o período em análise. Conforme ilustrado no Gráfico 20, antes de 2004, o percentual de invalidez no RPPS é muito superior. Essa divergência só diminui a partir de 2005, quando os efeitos da EC 41/03 podem ser identificados também em termos percentuais. Por isso, após a restrição imposta, os dados para o RPPS se aproximam do RGPS (urbano), 
apresentaram uma tendência de estabilidade em torno de 5,00\%. Cabe lembrar que a queda em 2003 foi em decorrência do efeito antecipação, já explicado no item III.2.1.

\section{Gráfico 20- Comparação entre o percentual de aposentadoria por invalidez no RPPS e no RGPS de 2001 a 2012}

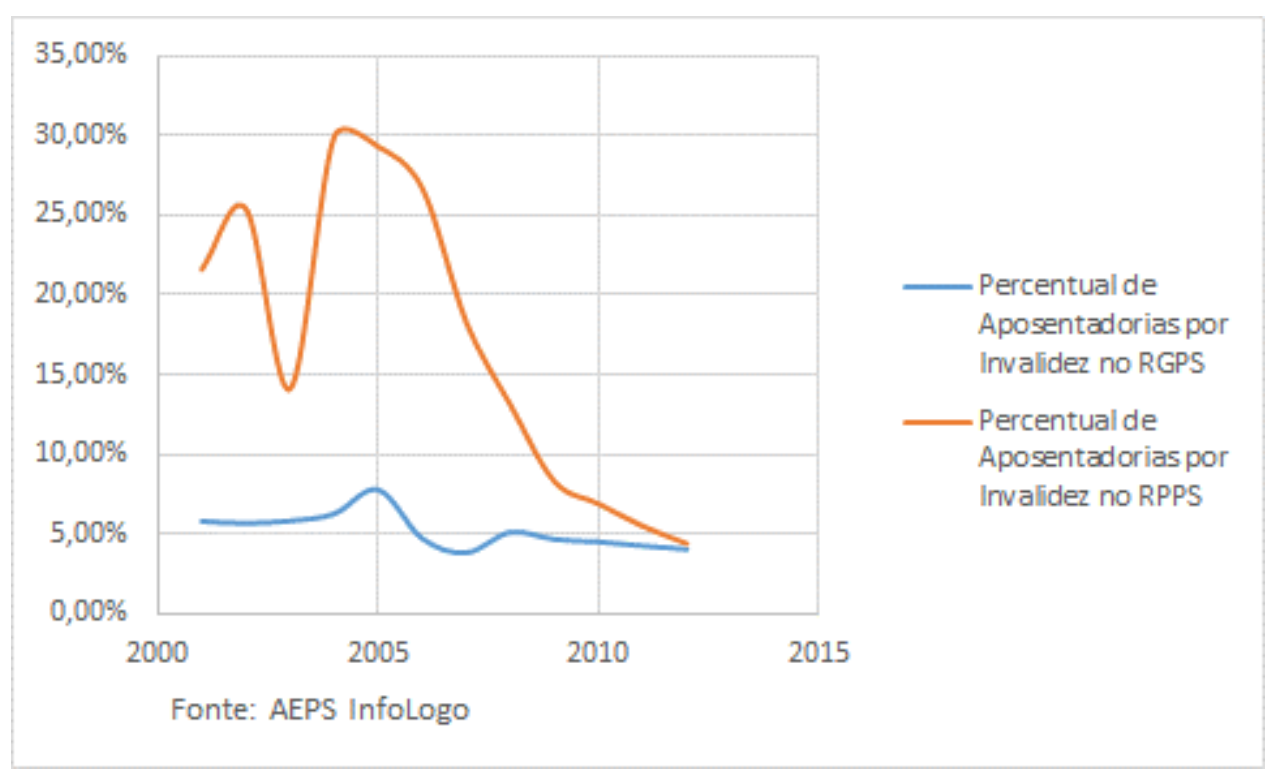

A partir de 2007, os percentuais do RGPS se estabilizaram abaixo de $5 \%$ e os do RPPS apresentaram declínio, fazendo a diferença entre eles diminuir para 0,29\% em 2012. Considerando os números do RGPS como parâmetro, o percentual de aposentadorias por invalidez deveria estar abaixo de $10 \%$ desde o início da série, em 2001. Porém, somente quando as regras de aposentadoria por invalidez se assemelharam, o comportamento nos dois grupos tornou-se próximo, como seria esperado.

Portanto, é correto deduzir que a primeira hipótese, a de que parte dos servidores anteriormente se aposentava indevidamente, seria mais plausível. Isso porque o número de aposentadoria por invalidez no RPPS era mais alto do que no RGPS e, após o desincentivo, veio a se assemelhar. Houve uma aproximação do caso em que não houve mudanças, ou seja, do esperado, e a diferença anterior seria então o risco moral.

A queda acentuada no número de aposentadorias por invalidez permitiu ao governo uma economia ao postergar a possível contratação de servidores que viriam a substituir os que desistiram de se aposentar. Entretanto, a mudança de regras também trouxe uma economia 
com os desafortunados que se tornaram inválidos, haja vista a redução no valor dessa aposentadoria. 


\section{CONCLUSÃO}

Esta dissertação testou a hipótese de efeito nulo da EC 41/03 no número de aposentadoria por invalidez. Para tal, apresentou as alterações nas normas provocadas por ela, identificando o caráter restritivo. Também foram estudados modelos para medir os impactos provocados por alterações de regras, de condições de saúde e de realizações de perícia médica na utilização de benefícios e no mercado de trabalho.

Em relação ao aspecto saúde, apesar da mortalidade ter caído, o uso de cuidados médicos e os gastos públicos com saúde mantiveram-se estáveis. A respeito da perícia médica, tanto o número de exames quanto os gastos subiram, mas não foram acompanhados por um aumento na identificação de fraudes.

As únicas alterações encontradas dizem respeito aos impactos no mercado de trabalho e na utilização do benefício provocados pela nova legislação. Enquanto o incentivo à permanência do servidor aumentou a idade média de aposentadoria, a diminuição do benefício em caso de incapacidade diminuiu o número de aposentadoria por invalidez.

Considerando que o número de aposentadoria por invalidez no setor público era mais alto que no setor privado antes da EC 41/03 e passo a assemelhar-se após a restrição nas regras, foi possível aceitar a hipótese de que o rigor diminuiu o risco moral. Ou seja, desestimulou aqueles sem uma doença de se aposentarem por invalidez.

Sendo assim, a hipótese de que servidores com doenças incapacitantes passaram a prolongar sua permanência no serviço, evitando ao máximo esse tipo de aposentadoria, pode ser refutada. Isto fica mais claro a partir de 2007, quando os percentuais do RGPS e do RPPS se estabilizaram em torno de 5\%, fazendo a diferença chegar a menos de 1\% em 2012.

Tal fato pode ser considerado uma economia para o governo. Isso porque os servidores que iriam se aposentar sem as devidas qualificações, foram desestimulados e desistiram. Fica claro apenas que as alterações nas regras afetaram justamente os trabalhadores que realmente teriam direito ao benefício e agora se aposentam em condições piores.

Também se pode questionar a conveniência da permanência de trabalhadores públicos que postergam sua saída ao evitar a aposentadoria por invalidez. Sobretudo por se duvidar da capacidade desses trabalhadores em manter sua produtividade em condições que acreditam ser classificadas como incapacitantes. 


\section{REFERÊNCIAS}

ANSILIERO, Graziela e DANTAS, Emanuel de Araújo. 2008. Comportamento Recente da Concessão e Emissão de Auxílios-Doença: Mudanças Estruturais? Informe de Previdência Social $\mathrm{n}^{\mathrm{o}}$ 11, v. 20, p. 6, Ministério da Previdência Social. Disponível em < http://www.previdencia.gov.br/arquivos/office/3_090227-161326-767.pdf >.

BATISTElla, Carlos Eduardo Colpo. 2007. Análise da Situação de Saúde: principais problemas de saúde da população brasileira. In: Angélica Ferreira Fonseca; Anamaria D'Andrea Corbo. (Org.). O Território e o Processo Saúde-Doença. Rio de Janeiro: EPSJV/Fiocruz, v., p. 121-158.

BERTRAND, Marianne, DUFLO, Esther e MULLAINATHAN, Sendhil. 2004. How Much Should We Trust Differences-In-Differences Estimates? Quaterly Journal of Economics $n^{\circ}$ 119: p. 249-275.

BRAGA, Breno G., GONZAGA, Gustavo e FIRPO, Sergio P. 2008. Escolaridade e o diferencial de rendimentos entre o setor privado e o setor público no Brasil. Rio de Janeiro: Pesquisa e Planejamento Econômico, v. 39, n.3, 2009.

FOGUEL, M. Diferenças em Diferenças. 2012. In: Naercio Menezes Filho (Org.). Avaliação econômica de projetos sociais. São Paulo: Dinâmica Gráfica e Editora, 1a ed., p. 69-83.

GOSMANN, M. C. 2014. Ciências atuariais aplicadas à previdência, in mimeo.

GRUBER, J. e D. Wise 1999. Social Security and Retirement around the World. University of Chicago Press: Chicago.

GRUBER, J. 2000. Disability Insurance Benefits and Labor Supply. Journal of Political Economy, 2000, vol. 108, no. 6, The University of Chicago.

GUPTA N. D., Lau D. e Pozzoli D. 2012. The Impact of Education and Occupation on Temporary and Permanent Work Incapacity. Bonn: Institute for the Study of Labor Discussion Paper No. 6963.

JOHANSON, P. e Palme, M. 2004. Moral Hazard and Sickness Insurance. Department of Economics, Stockholm University. 
JÖNSSON, L., Palme M. e Svensson, I. 2010. Disability Insurance- Population Healthand Employment in Sweden. National Bureau of Economic Research project International Social Security.

JÚNIOR, J. 2014. Comissão aprova aposentadoria integral por invalidez para servidor público. Disponível em < http://www2.camara.leg.br/camaranoticias/noticias/TRABALHOE-PREVIDENCIA/467977-COMISSAO-APROVA-APOSENTADORIA-INTEGRAL-PORINVALIDEZ-PARA-SERVIDOR-PUBLICO.html>.

KASSOUF, Ana L. 2005. Acesso aos serviços de saúde nas áreas urbana e rural do Brasil. Brasília: Rev. Econ. Sociol. Rural vol.43 no.1. Jan/Mar.

LEVITT, Steven D. e DUBNER, Stephen J. 2014. Think Like a Freak: The Authors of Freakonomics Offer to Retrain Your Brain. New York: William Morrow- HarperCollins.

MEYER, Bruce D. Natural and Quasi-Experiments in Economics. Journal of Business and Economic Statistics 13, no. 2 (1995): 151-161.

MINISTÉRIO DA PREVIDÊNCIA SOCIAL. 2014. Anuário Estatístico da Previdência Social. Disponível em <http://www.previdencia.gov.br/estatisticas/>.

MINISTÉRIO DA PREVIDÊNCIA SOCIAL. 2009. Anuário Estatístico da Previdência Social. Disponível em <http://www.previdencia.gov.br/estatisticas/aeps-2009-secao-xivprevidencia-complementar/>.

MINISTÉRIO DA PREVIDÊNCIA SOCIAL. 2014. Perguntas Frequentes - Previdência Social. Disponível em <http://www.previdencia.gov.br/perguntas-frequentes-previdnciasocial/>.

MINISTÉRIO DO PLANEJAMENTO, ORÇAMENTO E GESTÃO. 2014. Boletim Estatístico de Pessoal e Informações Organizacionais do Ministério do Planejamento, $\mathrm{n}^{\circ}$ 213. Disponível em < http://www.servidor.gov.br/index.asp?index=82\&ler=s1025>.

NAJBERG, S. e IKEDA, M. 1999. Previdência no Brasil: Desafios e Limites. In: GIAMBIAGI, F.; MOREIRA, M. (Ed.). A economia brasileira nos anos 90. Rio de Janeiro: BNDES, cap3, p. 261-290.

PINHEIRO, V. 2002. Previdência no Serviço Público: Evolução Recente. Informe de Previdência Social Volume 14, $\mathrm{n}^{\mathrm{o}}$ 07, Julho de 2002. Disponível em <http://www.previdencia.gov.br/arquivos/office/3_081014-104510-076.pdf>. 
SECRETARIA DE ESTADO DE EDUCAÇÃO DO DISTRITO FEDERAL. 2014. Alterações Constitucionais das Regras de Aposentadoria. Disponível em <http://www.se.df.gov.br/recursos-humanosnormas/362-alteracoes-constitucionais.html>.

SOARES, J. M. Aposentadoria por Invalidez no Regime Próprio de Previdência Social. 2012. Disponível em <http://blog.braconsultoria.com.br/aposentadoria-por-invalidez-noregime-proprio-de-previdencia-social-ec-7012/>.

WOOLDRIDGE, I. 2007. What's New in Econometrics? Difference-in-Differences Estimation. Lecture Notes 10, Cambridge: National Bureau of Economic Research. Disponível em < http://www.nber.org/WNE/lect_10_diffindiffs.pdf $>$. 